\title{
Las redes sociales rumanas en Coslada: un espacio de encuentro intercultural
}

\author{
Luz M. Buitrago, Camilo Bonilla, Amelia Cadenas \\ Nayra Leal, José Luis Parejo, Verónica Restrepo
}

\section{Resumen}

El presente documento recoge la identificación de las redes sociales existentes en el seno de la población de origen rumano en Coslada y el análisis de los mapas sociales obtenidos tras ese proceso de identificación, para llegar posteriormente a el análisis de los conjuntos de acción que se establecen en relación con la creación de un Espacio de Encuentro Rumano en Coslada, en el marco de la investigación participativa "Espacio de encuentro intercultural: caminando hacia la convivencia en Coslada", 2004-2005.

Palabras clave: Análisis de redes sociales - Sociograma - Conjuntos de acción.

\section{Abstract}

This paper examines the social networks of Rumanian residents in Coslada, showing the building of social maps to describe the community. In the process, we identify several action sets that are useful to design a Rumanian intercultural space in Coslada. This was part of a participative action research called "Espacio de encuentro intercultural: caminando hacia la convivencia en Coslada".

Key words: Social networks analysis - Sociogram - Action sets.

El artículo que se presenta a continuación sobre la identificación y el análisis de las redes existentes en la población de origen rumano de Coslada, es una parte del trabajo de investigación realizado durante los años 2004 y 2005 por un equipo del Magíster en Investigación participativa para el desarrollo local de la Facultad de Ciencias Políticas y Sociología de la UCM. Esta investigación se llevó a cabo a través de un convenio que suscribió el Magíster con el Ayuntamiento de Coslada, a través de la Concejalía de Atención al Ciudadano, Participación Ciudadana y Cooperación al Desarrollo. La demanda realizada por dicha Concejalía pretendía avanzar en una de las líneas de actuación identificadas en el estudio: "Participación de la población de origen rumano en Coslada" realizado por otro equipo de investigación del Magíster en el curso 2003/2004, con relación a la posibilidad de concreción de un Espacio de Encuentro Intercultural ${ }^{1}$ que fuese punto de referencia para los rumanos de Coslada.

\footnotetext{
${ }^{1}$ A partir de ahora, Espacio de Encuentro.
} 
En el diagnóstico participativo y en los encuentros de creatividad social realizados en el 2004 se puso de manifiesto que los cosladeños de origen rumano estaban interesados en participar en la mejora de su propia imagen, preservando su identidad cultural, favoreciendo el intercambio cultural, difundiendo e intercambiando información, potenciando actividades de ocio y tiempo libre, así como crear un Espacio de Encuentro. A partir de lo anterior, se llevó a cabo la construcción de un Programa de Acción Integral donde se estableció la importancia para los rumanos "de hacer oír su voz". Por ello, se consideró que la creación de un Espacio de Encuentro y la mejora de la imagen del colectivo eran temas muy importantes que sensibilizaban a la mayoría de la población rumana del municipio y que, por ello, podrían vincularse al proceso de planificación y ejecución de este proyecto.

Un hecho social que conviene tener presente para situar este proceso participativo es el progresivo aumento de la inmigración de origen rumano en España y especialmente su considerable asentamiento en la Comunidad de Madrid en la zona del Corredor del Henares, esencialmente en el municipio de Coslada. Un dato estadístico significativo es que para el año 2004 la población rumana constituía el $9,66 \%$ de la población total del municipio de Coslada².

En este sentido, se identificó que el aumento de la población rumana en el municipio y la ocupación de los espacios públicos de la ciudad, como las plazas, calles, parques, pistas polideportivas, etc. Es ésta una situación llamativa pero habitual para el resto de la población cosladeña, aunque en ocasiones provoque recelos. Ciertamente, las condiciones de los inmigrantes rumanos no son homogéneas, pero cada vez con mayor frecuencia se visibiliza las situaciones de marginación y pobreza de una parte del colectivo, contribuyendo esto a propagar la mala imagen que del mismo se tiene por parte del resto de la población. Este escenario plantea "la necesidad y la motivación" de los rumanos y de la Concejalía por crear un Espacio de Encuentro que genere un "diálogo de saberes", donde se aprenda de la sociedad receptora, y se enseñe y potencie la cultura propia, fomentando la convivencia entre los diferentes colectivos.

\footnotetext{
${ }^{2}$ Coslada es un municipio madrileño situado a 12 kilómetros al sur-este de Madrid en el llamado "Corredor del Henares". La superficie de la ciudad es de $11,7 \mathrm{Km}^{2}$ y cuenta con una población estimada de 90.000 habitantes, favorecido esto por el importante flujo migratorio que acoge. Es importante señalar el acelerado crecimiento demográfico experimentado en el municipio, pues se sitúa en un $400 \%$ cada diez años (en 1950 la población era de 899 habitantes, en 1975 con un 33.434, en el 2005 con unos 90.000 habitantes).
} 
En este sentido, surge la propuesta formal de la Concejalía a la UCM para continuar el proceso participativo con el fin de promover la participación de los cosladeños de origen rumano en la creación y organización de un Espacio de Encuentro.

Para hacer posible la creación de ese Espacio de Encuentro, no circunscrito solamente a poner a disposición un espacio físico, sino por una parte, a llenarlo de contendido con la participación de sus protagonistas y por la otra, articular y dinamizar las redes rumanas en Coslada para la organización de este espacio. El equipo de investigación consideró fundamental dedicar buena parte del trabajo a profundizar en el conocimiento de las redes sociales que componen la comunidad de origen rumano, partiendo de la identificación de los diferentes discursos inherentes a cada red social y buscando articular esas redes en el proceso participativo emprendido.

Para ello dentro de la metodología participativa llevada a cabo, se priorizó el uso de una serie de herramientas que permitían trabajar en clave de redes como ha sido el sociograma. Se realizaron sucesivos sociogramas de las redes que se iban identificando, a manera de radiografías de la situación de las redes en momentos específicos, su evolución y cambio a lo largo del estudio. Es importante hacer dos precisiones en cuanto al uso del sociograma: la primera, que era esencial su graficación a parte del encuadre estructural, dar cuenta de las posiciones (ideológicas, programáticas, etc) que cada grupo y/o red tenían en relación a su afinidad con el tema objeto de estudio, ya que las redes se posicionan de diferente forma según sea el tema de que se trate. Por tanto era importante distinguir los diferentes posicionamientos de las redes frente a lo que se quería construir a partir del espacio de encuentro. En segundo lugar, que la utilización de esta herramienta a lo largo del trabajo, permitiera la identificación y articulación de los conjuntos de acción para poder llevar a buen puerto el Espacio de Encuentro.

También cabe mencionar que para continuar la identificación de las redes, fue fundamental la realización de recorridos de observación por el municipio de Coslada, para poder establecer los espacios dónde se ubican esas redes. Para ello se hizo uso de algunas técnicas del Diagnóstico Rápido Participativo, como fue el mapa parlante que a continuación se describe. A partir de la identificación de esos espacios se realizaron charlas informales, entrevistas que permitieron ir complementando los sociogramas, conocer los discursos que representaban y el tipo de relaciones que se establecían, entre otras. 


\section{Distribución y uso del espacio público por parte la población de origen rumano en el municipio: el Mapa Parlante}

El mapa parlante realizado por el Equipo Técnico viene a ser el reflejo de la "observación participante" y del análisis de fuentes secundarias en cuanto a la convivencia del colectivo rumano en los espacios públicos de diferentes zonas de la ciudad: número de población rumana en las zonas de escolarización del "Casco" de la ciudad (Colegio "San Pablo"), en la de "Valleaguado Sur" (Colegio "Séneca") y en la de "Valleaguado Norte" (Colegio "Torres Quevedo"). Un aspecto importante desde el punto de vista convivencial es la existencia del Programa de "Escuelas de Bienvenida" consistente en el funcionamiento de aulas de enlace que posibilitan el conocimiento del idioma español al alumnado inmigrante ${ }^{3}$. En los IES “María Moliner" y "Miguel Catalán" se han puesto en marcha también el programa con un total de 22 alumnos hasta la fecha.

En lo referente a la base social no organizada tenemos que señalar que su actividad y presencia en la ciudad no es menor que la organizada. En el ámbito asistencial, la población rumana recién llegada se beneficia de los recursos que ofrecen Cáritas (Parroquia de San Pedro y San Pablo), Cruz Roja y ADRA (Avda. Roma - Ciudad 70) y los Servicios Sociales del Ayuntamiento. En el ámbito recreativo o del ocio y tiempo libre es importante advertir que el deporte es una actividad muy valorada en el colectivo rumano, a ello se debe el uso que hace la población joven rumana de Coslada los fines de semana de las pistas polideportivas municipales como es el caso de las del "Casco" (situadas al lado de las piscinas), el recinto ferial y la "Plaza de la Hispanidad".

Por otra parte, los locutorios son unos negocios que se utilizan, además de para comunicarse con el país de origen, para mantener relación con otros compatriotas o de otras nacionalidades. Por tanto, son un centro de socialización por ser un flujo importante de demanda de información: empleo, vivienda, etc. Los locutorios que acogen a un mayor número de clientes rumanos son los situados en el "Casco" y, en menor, medida en el Barrio de "la Cañada". Pero son ciertas calles y plazas de la ciudad las que se convierten en un verdadero centro social rumano, como es el caso de la Plaza del Sol, situada en pleno Casco urbano de la ciudad, donde se concentra una gran masa de rumanos recién llegados que solicitan empleo y otros rumanos o españoles que ofertan empleo, también es un lugar donde se habla con los iguales y se descansa, pues en muchos casos las condiciones de habitabilidad son precarias y se carece del espacio vital necesario. Esta plaza es un foco visible

\footnotetext{
3 Los destinatarios de este programa son los alumnos de los ciclos segundo y tercero de educación primaria y los de educación secundaria de centros sostenidos con fondos públicos (colegios de titularidad pública y privada concertada).
} 
de la actividad de muchos rumanos no asentados que se ven forzados a utilizarla con los fines antes señalados. También se origina algo interesante, que es la coexistencia en el mismo espacio físico de los rumanos y los cosladeños jubilados, hecho que genera una estampa bastante interesante y peculiar desde el punto de vista sociológico. Destacar también otras formas de descanso y distensión de muchos rumanos que suelen pasear por el Lago de "las Ramblas", el Centro Comercial "Los Valles" así como comer en restaurantes rumanos del "Casco" y de la Avenida de los "Príncipes de España".

Otros lugares interesantes son los comercios regentados por rumanos, las pastelerías "patiserias", que son un tipo de negocio muy común en esta población rumana. Se encuentran también en torno al "Casco" como se puede observar en el mapa parlante que presentamos a continuación. También en el ámbito organizativo las Iglesias son un foco de socialización y encuentro bastante importante, cabe mencionar la Iglesia Adventista ("Casco" y "Ciudad 70") y las I glesia Evangelistas. Por otro lado, el Centro Sociocultural "La Bufanda" acoge tanto a la Asociación Cultural Obatalá como a la Asociación de Rumanos de Coslada-San Fernando ("Casco") y el Centro Municipal "El Cerro" a la Asociación de Rumanos Transilvania.

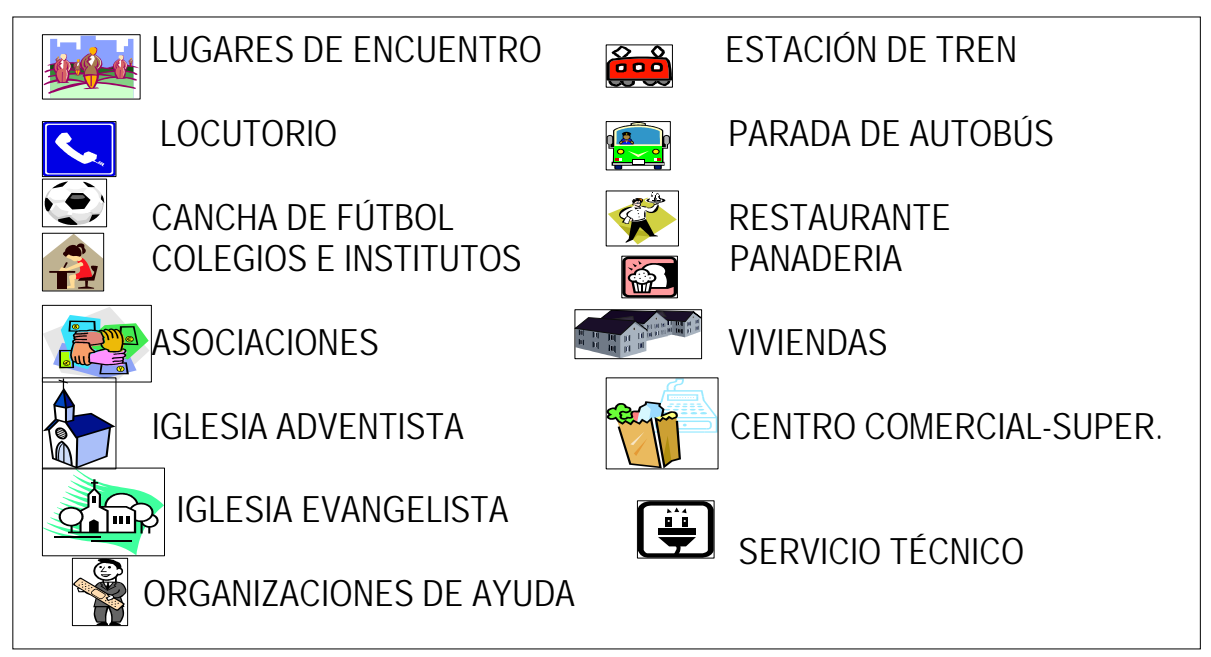

Leyenda mapa parlante 


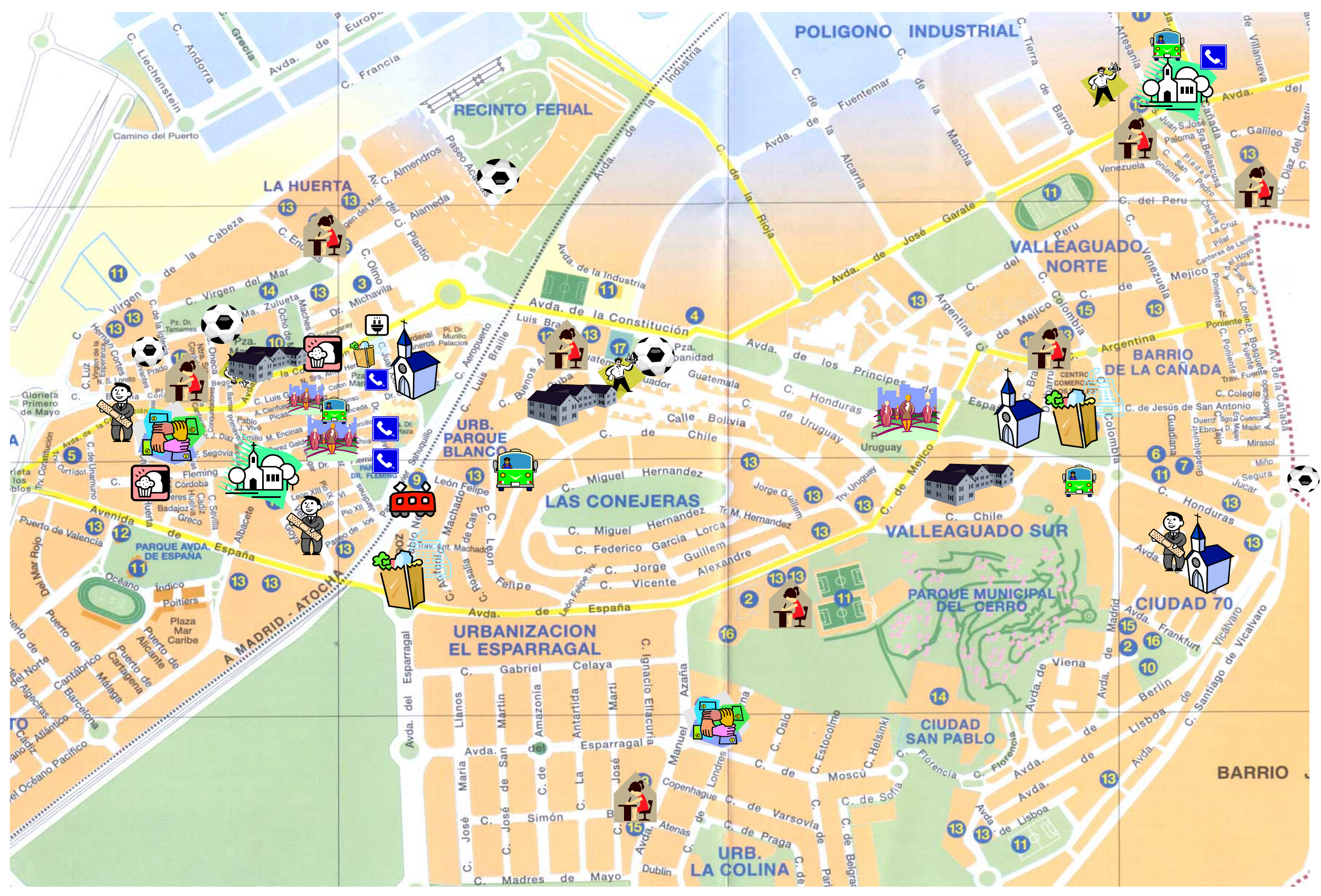

I lustración 1. Mapa Parlante 


\section{El sociograma y su evolución a lo largo del proceso}

En este apartado vamos a describir la evolución que ha sufrido el sociograma desde la investigación realizada en los años2003-2004 hasta el final de la investigación (julio de 2005). Esto lo hacemos con la intención de explicar las diferentes transformaciones que ha sufrido el análisis de redes sociales en la medida que hemos ido profundizando en las relaciones de los rumanos y su complejidad, ya que han aparecido nuevos actores sociales, mientras que otros han cambiando. Enumeraremos las transformaciones desde arriba hacia abajo.

En primer lugar, vale la pena mencionar algunas modificaciones que se han hecho sobre las formas de las redes y las relaciones. En cuanto a estas últimas distinguimos que algunas redes se relacionan de forma puntual, en la medida que no son constantes y se diferencian de las débiles en que no son frágiles sino periódicas. También hemos cambiado el símbolo de los representantes eclesiásticos con el fin de diferenciarlos de las asociaciones, al igual que el de las Organizaciones No Gubernamentales.

También podemos observar que en el último sociograma incluimos a los tres equipos de trabajo que están realizando investigaciones con esta población, dentro de los cuales estaríamos incluidos nosotros mismos, puesto que en el momento actual somos unas redes que estamos participando de la realidad y potenciando su transformación. 


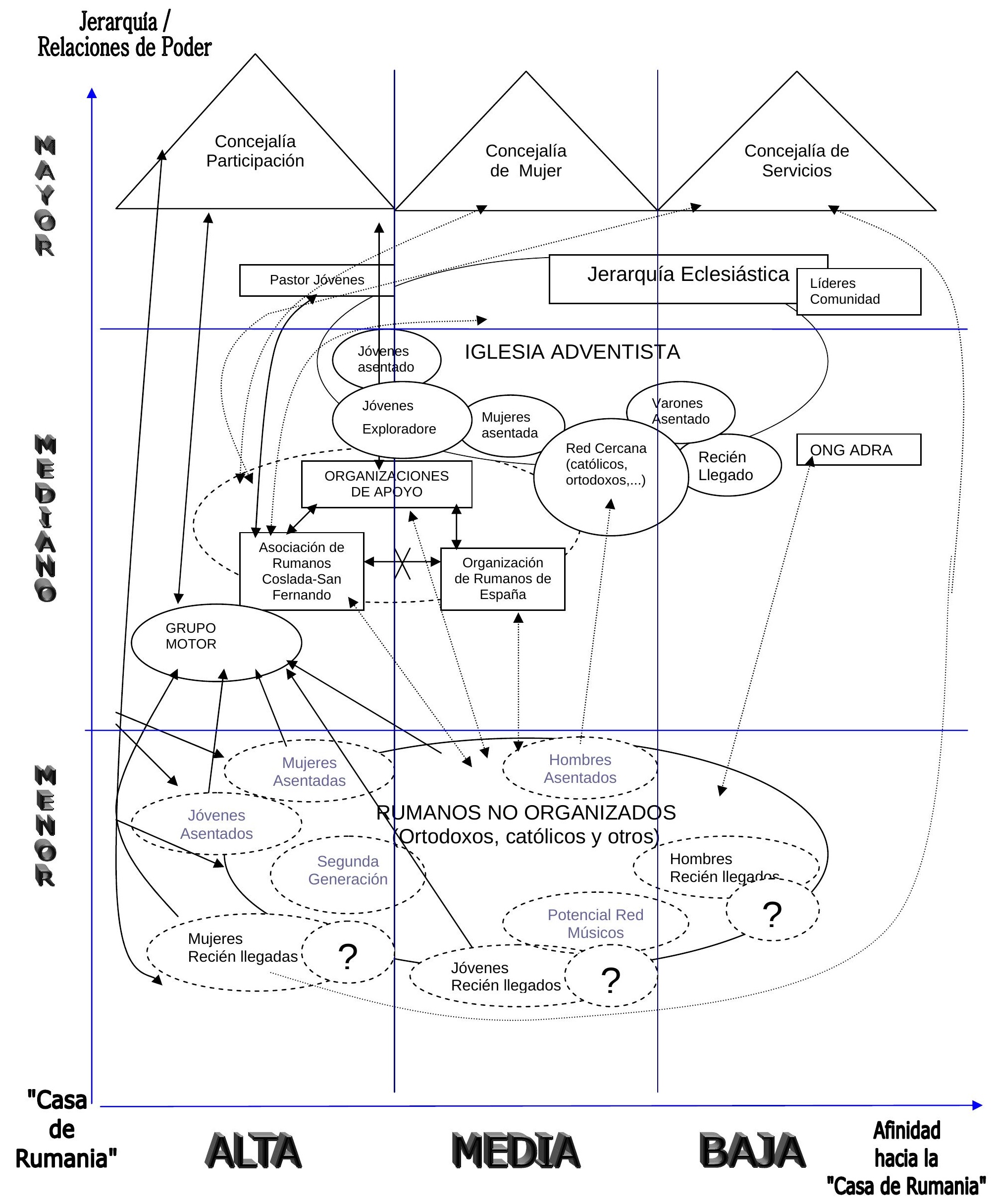


Jerarquía /

Relaciones de Poder

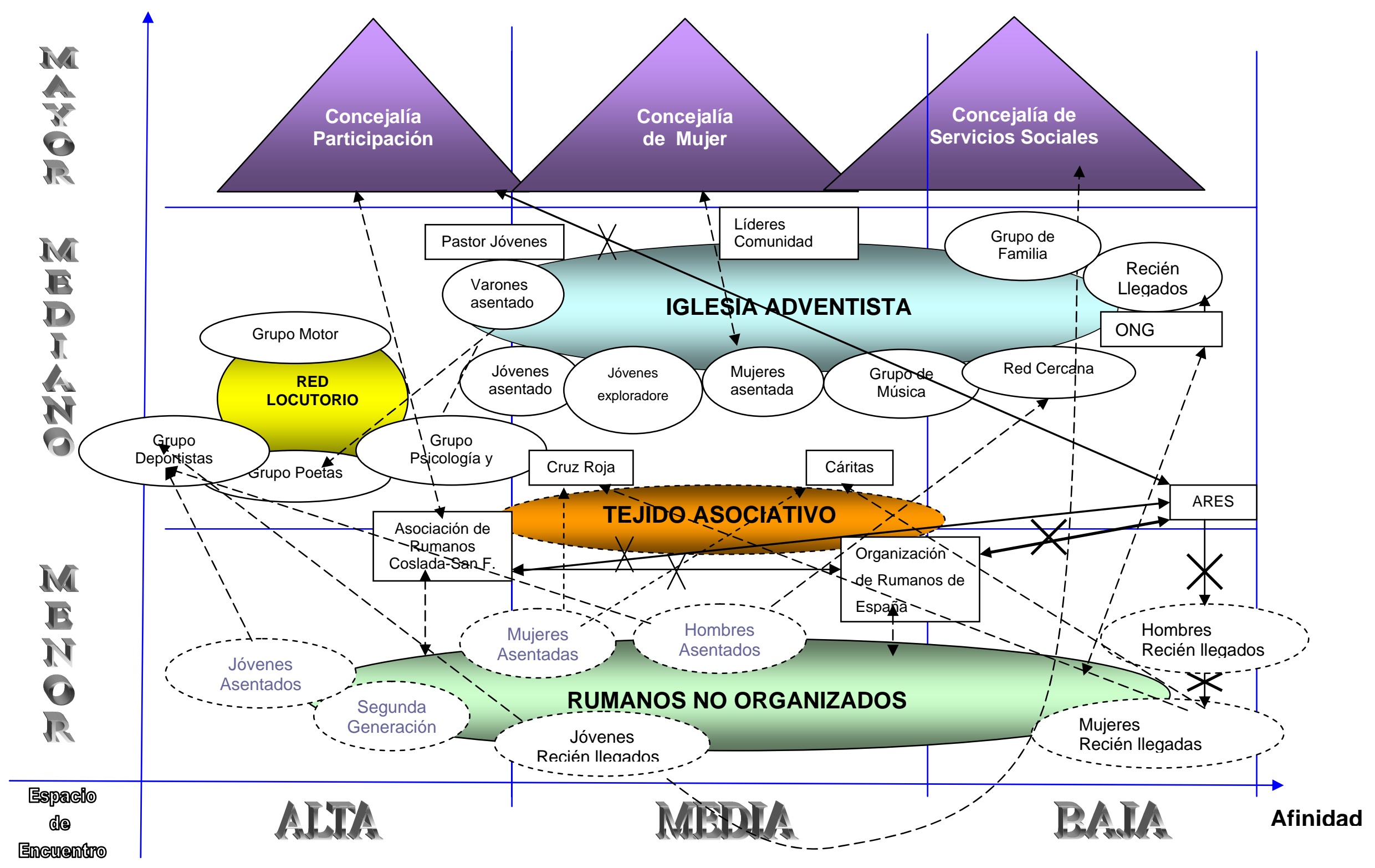




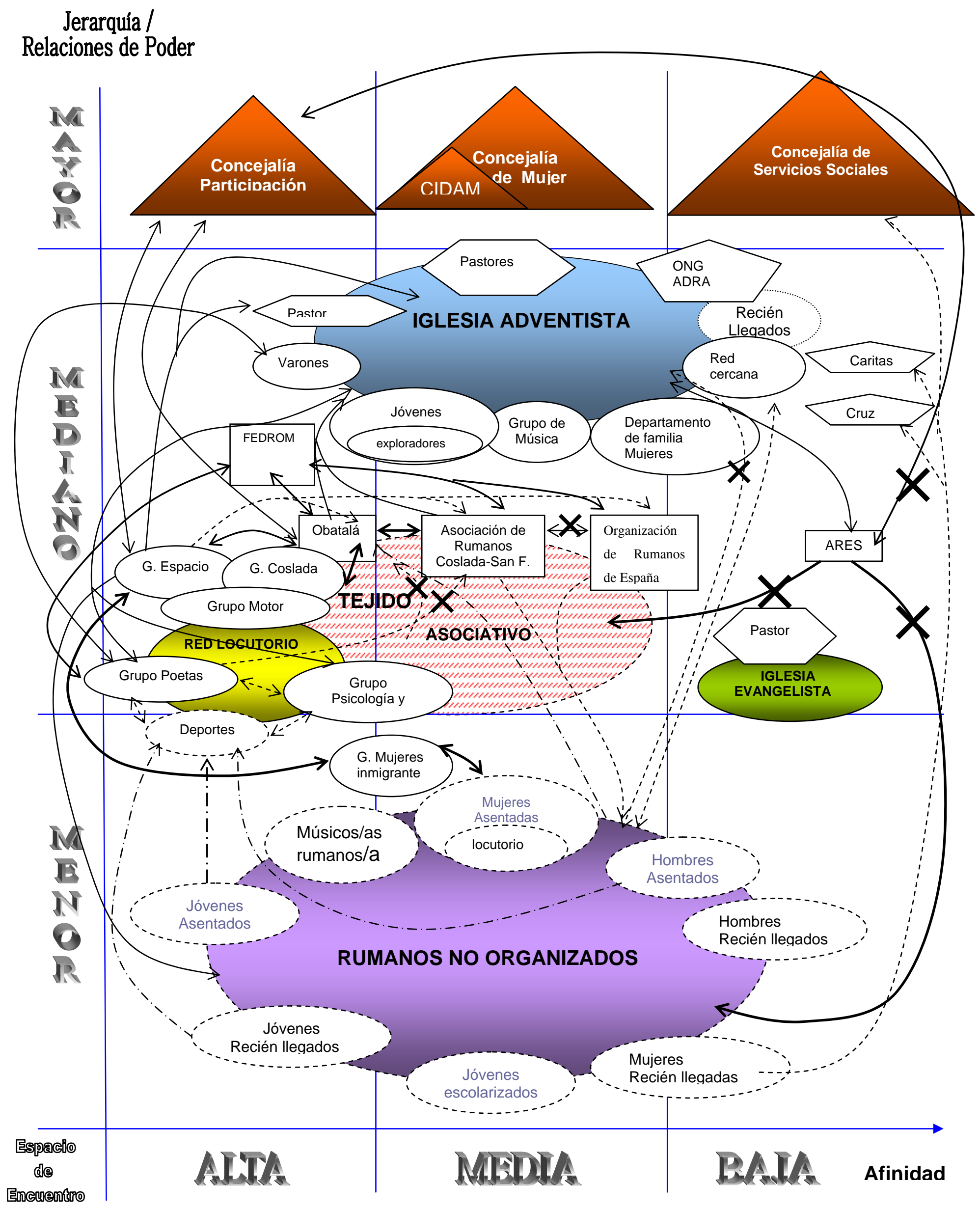




\section{Jerarquía /}

\section{Relaciones de Poder}

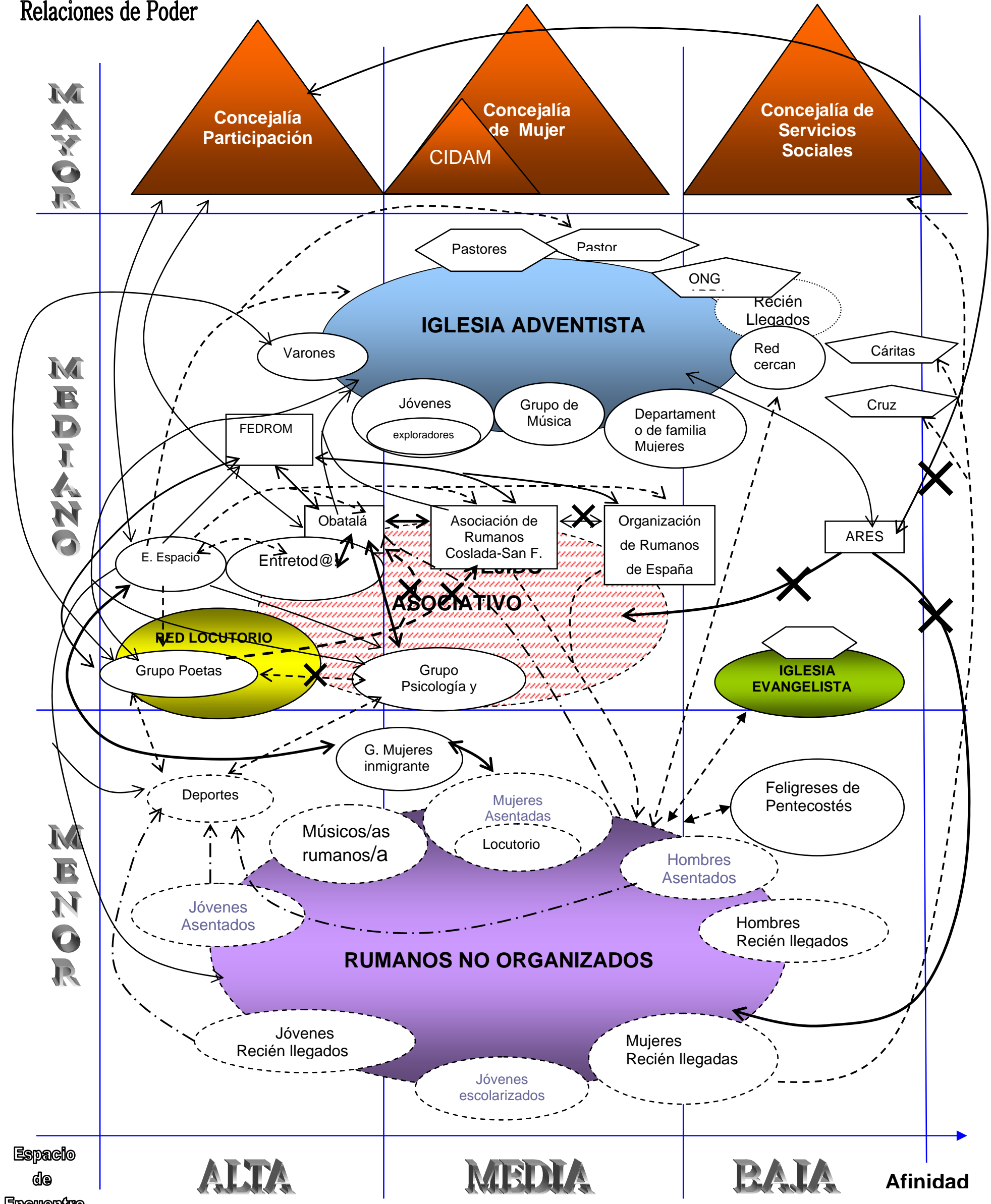




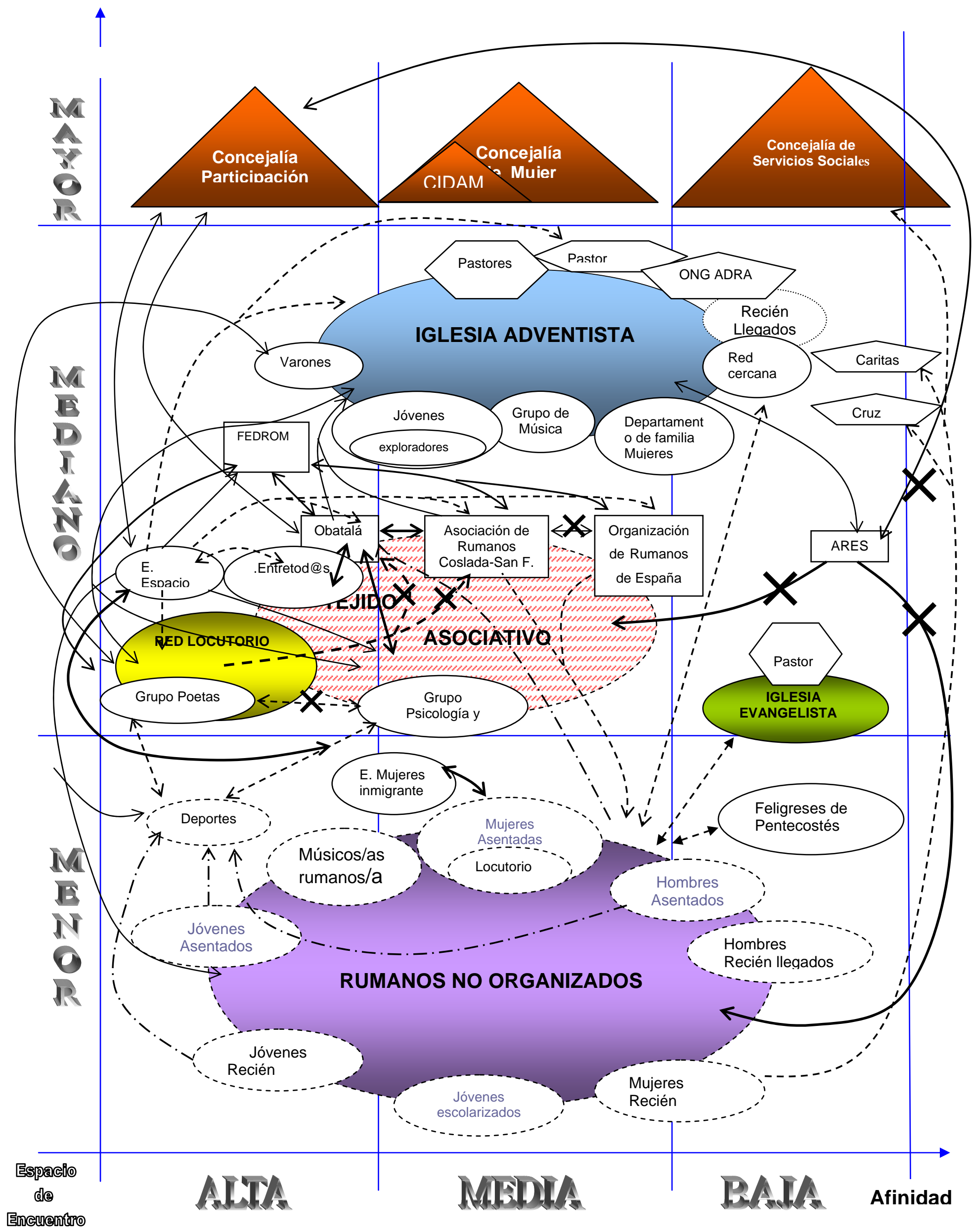




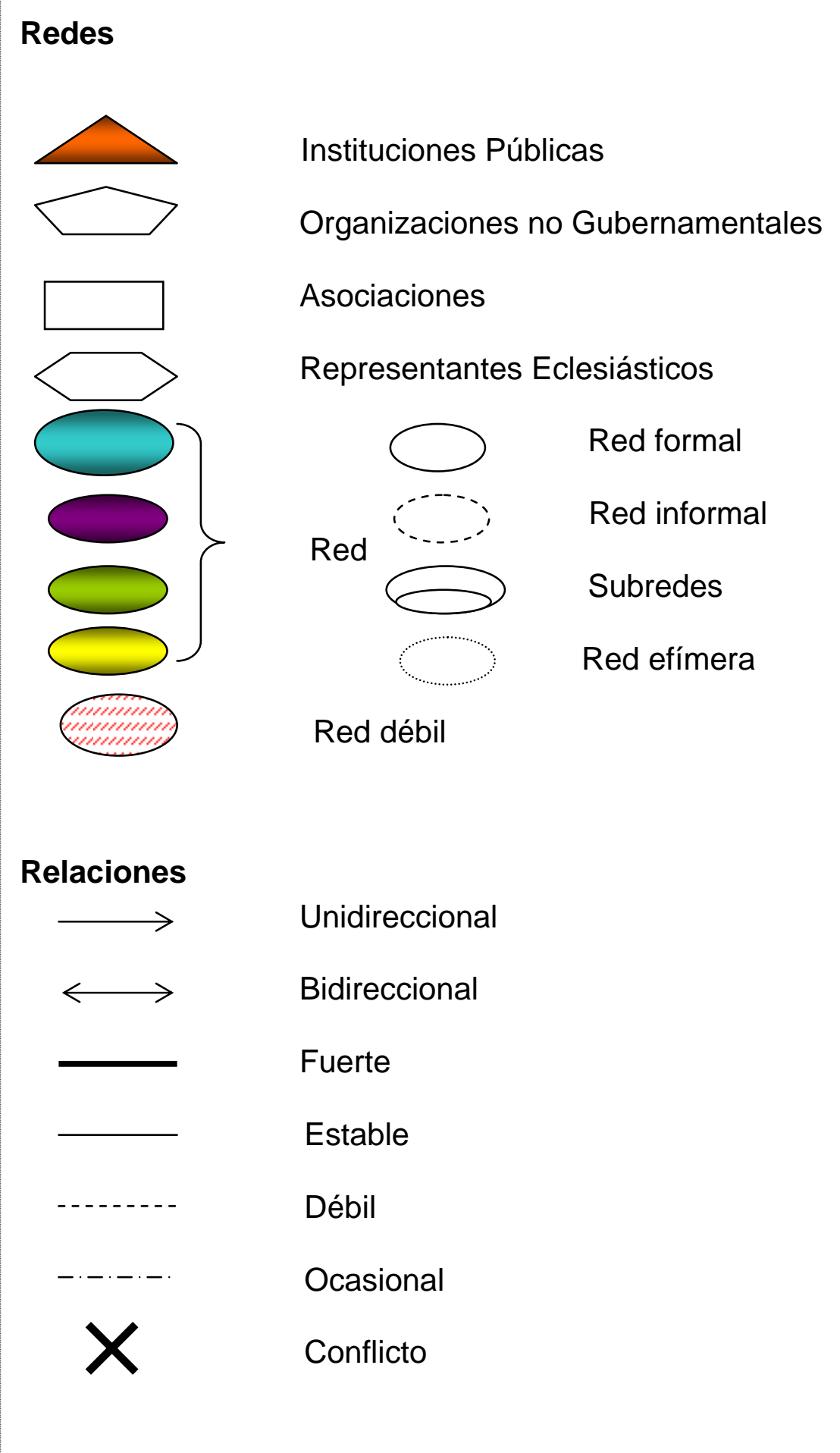


En la parte superior de los sociogramas se encuentran la Concejalía de Mujer y la de Servicios Sociales que se han desplazado hacia la derecha debido a que han pasado a tener una menor afinidad con el objeto de estudio. Además, hemos introducido dentro de la Concejalía de Mujer al CIDAM ya que está interesado en trabajar con mujeres inmigrantes y es el promotor de la investigación del Equipo de Investigación que trabaja sobre este tema.

La red adventista ha sufrido cambios significativos debido a que se ha profundizado en el conocimiento de la organización y relaciones de ésta, lo cual ha dado lugar a identificar nuevas subredes que se articulan en su interior. Éstas son el grupo de exploradores que se sitúa del grupo de jóvenes, grupo de familia y, finalmente, el grupo de músicos, el cual se había ubicado en un principio en la red de rumanos no organizados, pero tras el trabajo de campo se ha visto que esta subred se apoya en la red adventista. Además, en las últimas semanas, hubo una rotación de pastores dentro de la I glesia Adventista, lo que hizo que el Pastor del grupo de jóvenes que estaba tan interesado en el proceso del Espacio de Encuentro no impulsara éste en su comunidad, y el actual no está muy interesado ni en éste ni en la participación de los rumanos en diversas actividades lúdicas y de convivencia. Por lo tanto, dada la capacidad de influencia que posee el pastor dentro de la red adventista podemos concluir que ésta no es ya tan afín al objeto de estudio.

En lo referente al tejido asociativo también se ha producido un desplazamiento hacia la derecha, debido a que hasta el momento no han mostrado tanta afinidad hacia nuestro objeto de estudio. Además, se le ha delineado con un borde punteado con el fin de mostrar que no está consolidado todavía, pues no tienen una base social sólida. Hemos incluido a la Asociación Cultural Obatalá por su importancia en el trabajo que realiza con el Equipo de "Entretod@s” y por su papel en las clases de español. También a la Federación Española de Asociaciones de Rumanos (FEDROM) puesto que posee una relación importante con el tejido asociativo rumano, con el grupo “Centro Academia Metáfora” y, además, porque ha demostrado interés en la creación de un futuro Espacio de Encuentro en Coslada.

I dentificamos otra organización llamada ARES que hasta el momento no era visible, la cual se encuentra enfrentada con la Concejalía de Participación y rechaza trabajar con población rumana en situación de irregularidad. Igualmente, se ha incorporado a Cáritas y a Cruz Roja, debido a que se ha detectado que las mujeres recién llegadas que pertenecen a los rumanos no organizados se benefician asistencialmente de sus actividades. 
Uno de los cambios fundamentales ha sido la aparición de una nueva red, llamada Red Locutorio, donde se encuentran nuevos grupos que se han creado gracias a la difusión del proyecto de investigación, y la conforman las personas más identificadas con el objeto de estudio. En donde se conformó un nuevo grupo motor, que no es el mismo que se había señalado al inicio de la investigación, ya que éste ha desaparecido o se ha desintegrado. Igualmente, se han identificado algunos conflictos y prejuicios de ciertos miembros del grupo motor con las asociaciones de Obatalá y la Asociación de Rumanos de Coslada y San Fernando.

No obstante, como hemos mencionado esta red tuvo dificultades en la última etapa de trabajo y algunos grupos se desligaron. Por lo tanto, esto también se evidencia en el sociograma, donde el grupo de deportistas se acerca más a la red convivencial de los rumanos no organizados, la red de "Trabajo Social y Psicología" se acerca y empieza a relacionarse con la Asociación Cultural Obatalá, y por último, la red del locutorio es el grupo de "Centro Academia Metáfora".

En lo referente a los rumanos no organizados, se han incorporado nuevos grupos, como la red de músicos y músicas rumanas que podrían estar interesados en participar de este futuro Espacio de Encuentro. A su vez, dentro de esta red, se ha ubicado una subred de mujeres que se reúnen ocasionalmente en un locutorio.

También hemos observado la existencia de tres nuevas organizaciones religiosas: la Iglesia Baptista, la Iglesia Pentecostés y la Iglesia Evangelista. Incluimos en el sociograma a la Iglesia Evangelista porque hemos contactado con ellos, sin embargo, no hemos profundizado en sus relaciones. Además, incluimos a los creyentes de Pentecostés, pues hemos comprobado que viven en Coslada y conviven con las otras redes rumanas, pero tampoco hemos logrado profundizar en sus relaciones, por lo cual se ha simbolizado con unas flechas débiles. Por último, consideramos que es pertinente no incluir en el sociograma a la Iglesia Baptista, pues nos ha quedado por explorar.

\section{Redes Sociales}

En este capítulo analizaremos las redes sociales de los cosladeños de origen rumano con el fin de identificar las posibilidades y dificultades existentes en dichas redes para que puedan llevar a cabo el proyecto común propuesto por éstas. Por ello, es importante conocer las redes, sus necesidades, intereses, imaginarios y proyectos en relación a un espacio común, al igual que las relaciones de poder existentes, pues todos estos factores determinarán la forma en que se desarrolle el proceso participativo. 
El análisis que a continuación desarrollamos pretende ser un avance desde el primer acercamiento a esta comunidad que se hizo por parte de la investigación del año anterior. Por tanto, una tarea de la presente investigación es la de continuar profundizando en las redes ya definidas así como en las nuevas identificadas para conocer exhaustivamente sus diversas formas de configuración, estructuración y relaciones entre sí en torno al objetivo concreto de construir un Espacio de Encuentro que promueva la participación del colectivo rumano y la convivencia con la sociedad receptora.

Las redes no son homogéneas, están en continuo movimiento $y$, por esto mismo, en continua fragmentación y reconstrucción. De ahí la importancia de conocer estas redes y cómo conviven sus miembros entre sí a fin de poder ir desvelando las formas de organización social de una heterogénea comunidad rumana que se establece lejos de su lugar de origen.

Para ahondar en la configuración de las redes sociales realizaremos un análisis posicional, identificando los actores más visibles y cohesionadores de las redes. Además, lo complementaremos con un análisis relacional para poder identificar cómo se van estableciendo las relaciones menos institucionales. En este sentido, comenzaremos esta tarea desde las redes más visibles y cohesionadas hasta las menos organizadas.

\section{A. Red articulada en torno a la I glesia Adventista}

En la primera investigación social participativa realizada con los cosladeños de origen rumano se pudo constatar que la red más visible, debido a su alta articulación y cohesión, corresponde a los rumanos adscritos a la religión adventista. Por ello, si hablamos de participación, en cuanto a la presencia activa de los rumanos en actividades que satisfacen sus necesidades y les motivan, debemos hacer referencia a la Iglesia Adventista. Esta red posee una organización social jerárquica debido a la posición central de los pastores en las relaciones y la vida cotidiana de los creyentes. Además es una religión que demanda un compromiso intenso de sus fieles, como por ejemplo, el deber de reunirse en todos los viernes y sábados para rezar el culto, así como llevar un estilo de vida determinado y coherente con unas normas estrictas que deben ser respetadas (prohibición de fumar o tomar bebidas alcohólicas, etc.).

En gran parte son las actividades organizadas por la Iglesia las que tejen las redes a su alrededor, lo que le da esa estructura consolidada y cohesionada a la red. La I glesia tiene un amplio abanico de actividades que va desde celebraciones litúrgicas y catequesis, pasando por las asistencialistas realizadas por la ONG ADRA, hasta las puramente socioculturales como el coro, fanfarria, grupo de exploradores, 
deportes, escuela sabática, charlas sobre familia etc. Todas ellas ocupan los espacios de ocio de sus fieles, donde se educa transversalmente en los valores adventistas. Esta circunstancia los aísla de las escasas actividades de ocio que posee el resto de la población rumana de Coslada no adventista o la demás población cosladeña.

Lo anteriormente expuesto denota que es una red cerrada, que mira hacia adentro. La excepción a esto sería el Pastor del grupo de jóvenes, quien muestra una actitud más abierta y está interesado en fomentar la convivencia de los adventistas con otras redes de rumanos y españoles, por lo cual siempre ha fomentado la participación activa de su comunidad. No obstante, por la actual rotación de Pastores cambia radicalmente esta situación, pues el nuevo Pastor no está muy de acuerdo con estos temas y no le interesa fomentar la participación en tal sentido, correspondiendo los fieles a su doctrina y, lo cual corrobora las relaciones jerarquizadas que posee esta red.

Las relaciones de la Iglesia con los jóvenes son más intensas, en la medida que éstos participan en mayor número de actividades y además han de enfrentarse a ciertas costumbres del ámbito social que son contrarias a la fe adventista. Esto es algo que ya se había identificado el año anterior y se confirma este año. Por ejemplo, un joven adventista que nos expresaba el interés por conocer jóvenes españoles pero que le era difícil por sus creencias religiosas. Sin embargo, uno de los proyectos futuros de la I glesia es crear un gran colegio Adventista en Coslada.

Ciertamente, los adventistas prefieren compartir sus mismos valores con rumanos que sean también de su misma religión, para así llevar un estilo de vida coherente con su fe. No obstante, hemos de afirmar que, desde el punto de vista convivencial, la Iglesia Adventista se sitúa como una red mucho más visible, articulada y organizada, frente a otras menos cohesionadas institucionalmente y mucho más heterogéneas.

\section{Las Subredes}

En el interior de la Iglesia no se habla de jerarquías, los pastores adventistas afirman que su funcionamiento se rige a través de una organización colegiada. Sin embargo, en el análisis se puede observar que a pesar de ello las relaciones sí son subordinadas entre los fieles y dirigentes espirituales. Además, se respeta mucho su conocimiento académico, cultural y espiritual.

En lo relativo a la organización de las actividades, hemos de señalar que la Iglesia planifica a través de un comité conformado por distintos departamentos. Por ejemplo, está el departamento de jóvenes, familia, tercera edad, salud, la escuela 
sabática (estructurada por edades) y la ONG ADRA. Hasta el momento, hemos podido identificar las siguientes subredes articuladas en torno a la Iglesia:

a) Subred Cercana

Podemos señalar que, tanto en el análisis del año anterior como en el trabajo de campo realizado para esta investigación, se ha detectado que existe un cierto número de rumanos que vienen a Coslada que por diversas razones deciden convertirse al Adventismo. Este comportamiento puede ser una forma de encontrar tranquilidad ante una situación de incertidumbre como es la que experimentan muchos rumanos al llegar a España. La ayuda de diversa índole ofrecida por la I glesia Adventista, a través de la ONG ADRA, al aportar facilidades adaptativas para solucionar dificultades como la alimenticia, la laboral y la habitacional parecen ser motivos más que suficientes para adherirse a una red muy cohesionada y con gran nivel de eficacia y eficiencia en cuanto a su funcionamiento. Una mujer asentada ortodoxa señala lo siguiente:

Sí, aquí hay muchos adventistas, pero la mayoría no eran adventistas en mi país, sino que se han convertido para venir aquí porque les dan beneficios (...). La Iglesia los ayuda (...), muchos son católicos, ortodoxos pero dicen ser adventistas para fuera (...). (Se ponen la mano en el corazón y hace una seña y repite) la mayoría son adventistas pero no de verdad, de apariencia.

b) Subred familia

Esta subred está compuesta por un grupo de mujeres que se articula en torno a las actividades organizadas por el departamento de familia, en las cuales se reúnen a rezar, tratar temas sobre la familia, compartir recetas culinarias, etc. Por un lado, hemos de señalar que estas mujeres conforman un grupo bastante heterogéneo en cuanto al nivel socioeconómico, ya que existen claras diferencias en la forma de vestir, en la habilidad y disposición para expresarse, etc. Por el otro, las mujeres que más expresan su opinión son las representantes en el comité.

c) Subred Jóvenes

La constitución de esta subred se basa en unos jóvenes que se reúnen los viernes por la noche para rezar el culto, compartir experiencias y organizar actividades. La mayoría son varones que han dejado los estudios para trabajar. Dentro de esta subred hay un grupo de exploradores: monitores y niños.

En general, se observa que todas estas subredes se tejen en torno las posiciones de los Pastores y los representantes de los departamentos. Y además, tienen la función de cohesionadores a partir de las actividades de ocio en el tiempo libre. Es por esto, que los adventistas tienen más claro la importancia de las actividades alternativas al trabajo y la necesidad de éstas en la cotidianidad urbana. 
d) Grupo de Música

Este grupo gira en torno a un profesor colombiano que dicta clases de música en las instalaciones de la Iglesia Adventista. Esta es una actividad formativa que se realiza dentro de las actividades coordinadas de la iglesia y se basa en el alto interés de esta comunidad en la referida manifestación artística tan importante para los rumanos. Según el profesor:

Los niños rumanos tienen un concepto alto de lo que es tocar bien, los padres también saben que es importante (...). Ellos invierten en música, les gusta, saben cuando está la música bien hecha, cuando está mal hecha, tienen cultura musical, entonces pues el contacto se hace muy fácil y muy directo desde el punto de vista musical.

Uno de los discursos significativos de este experto convivencial, es la perspectiva intercultural que se propone así como la existencia de vínculos de amistad y sentimientos de pertenencia:

Sentirnos que somos extranjeros y los extranjeros tenemos nostalgias, unas impresiones del país al cual hemos llegado, unas apetencias que nos vinculan, y que en el caso particular de los rumanos y al estar del medio también la Iglesia pues hace que sea más fácil establecer relaciones de amistad, de colegas y además hay metas comunes.

Vale la pena resaltar que este grupo no pretende ser excluyente con otras redes rumanas que no pertenezcan a la red adventista, aunque es difícil que participen ya que realizan su actividad dentro de los locales de la mencionada iglesia.

Por lo tanto, su enfoque podría estar encaminado hacia la convivencia, en la medida que plantea un proceso que va más allá de las redes rumanas, lo cual sería muy importante para lograr la necesidad expresada por los mismos rumanos de dar a conocer su cultura, compartir con la cultura receptora y mejorar la concepción que se tiene en Coslada sobre los rumanos.

\section{B. Grupos movilizados en torno al Locutorio (provenientes de otras redes)}

La cesión del espacio anexo a un Locutorio para poder llevar a cabo reuniones del proyecto y el apoyo del dueño del Locutorio, motivaron la creación de un grupo conformado por varias redes interesadas en el Espacio de Encuentro. Los componentes de esta red inicialmente eran grupos aficionados a la literatura y al deporte. Posteriormente, se fue incorporando un grupo de Psicología y Trabajo Social. 
Sin embargo, en las últimas etapas del proceso se empezaron a evidenciar diferencias muy marcadas en las percepciones de las actividades y en las formas de trabajar, por lo cual también empezaron a generarse dificultades para comunicarse. Por lo tanto, al final del proceso el Locutorio sólo siguió reuniéndose el grupo de "poetas". Entonces, el grupo de Psicología y Trabajo Social se describirá más adelante como una red separada del locutorio.

a) Grupo Satélite Literatura o de Poetas

Actualmente, podemos afirmar que el grupo de literatura esta interesado en constituir una asociación, y se denominan "Centro-Academia Metáfora". Este grupo está bastante consolidado, pues se reúnen los domingos durante dos horas para discutir y trabajar sobre poesía y literatura, además de utilizar el espacio durante la semana para coloquios. También, tiene gran capacidad de convocatoria por lo cual su problema actual es el espacio físico, ya que el local es pequeño y no cuenta con unos servicios adecuados.

Para este grupo es importante la convivencia de los rumanos, al respecto comentan lo siguiente "No se necesita una barrera entre nosotros, entre culturas, entre civilizaciones, entre edad (...). La puerta está abierta para todas las religiones, para todos los hombres, de cultura, estudiantes, profesores, trabajadores, etc., no importa quien venga a participar" (Dirigente del grupo).

Este grupo está compuesto mayoritariamente por adventistas pero tienen el interés de realizar actividades fuera de la iglesia y con rumanos de otras religiones, de ahí el calificativo como grupo "satélite", pues existe algunos miembros de otras religiones: "muchos de nosotros queremos salir de la atmósfera de la religión para trabajar sin una dirección precisa, simplemente por conocer". Sin embargo, en la práctica establecen otro tipo de distinciones como el título profesional y estatus cultural.

b) Grupo Satélite de Psicología y Trabajo Social

Este grupo surgió a partir del anterior, ya que difundió la idea de la creación de un espacio social y cultural rumano y un grupo de jóvenes decidió ponerse al frente de esta iniciativa y trabajar conjuntamente en el Locutorio. Como ya hemos mencionado, actualmente ya no pertenecen al grupo del locutorio y están empezando a realizar sus actividades con el apoyo de la Asociación Cultural Obatalá. Este grupo ha concretado tareas de apoyo a recién llegados y, en general, de información sobre deberes y derechos. También está colaborando en el Boletín Rumano de Coslada. 
c) Grupo o Subred Informal de Deportes

Esta subred se evidenció a la vez que la de la del grupo de "Literatura" y algunos de los jóvenes que la conforman colaboraron en la adecuación del espacio cedido en el ya mencionado locutorio. Un joven ortodoxo tomó la iniciativa de llevar a cabo un proyecto deportivo para la población rumana que se reúne puntualmente los domingos a jugar fútbol en todas las pistas polideportivas municipales de Coslada. Este grupo no es un "satélite", puesto que su representante no es adventista aunque compartía el interés intercultural de fomentar la convivencia de las otras redes articuladas en torno al locutorio. Actualmente, el responsable de este proyecto ha dejado de participar, por lo cual, al día de hoy no se incluye a esta subred dentro del grupo del locutorio, sino dentro de la base social no organizada.

d) Grupo Movilizado

Este grupo estuvo compuesto por las diferentes personas de los grupos del locutorio ya que eran los más interesados y cercanos al objeto de estudio, con los cuales se trabajó durante la etapa del diagnóstico y la devolución. En el trabajo realizado se empezaron a evidenciar las diferencias entre aquellos que lo conformaron, por lo cual, actualmente ya no existe un grupo cohesionado y se ha dividido en dos grupos de trabajo con espacios de reunión diferentes.

\section{B. Tejido Asociativo}

En lo relativo al tejido asociativo, existen en Coslada varias entidades que tienen como destinatario de su acción social a la población cosladeña de origen rumano. Destacaremos, por ello, a la Asociación de Rumanos de Coslada-San Fernando, la Asociación de Rumanos de España Transilvania, Asociación Cultural "Obatalá", Federación Española de Asociaciones Rumanas FEDROM y Asociación de Rumanos en España ARES.

En primer lugar, la Asociación de Rumanos de Coslada-San Fernando y Asociación de Rumanos de España Transilvana, según se identificó en la primera investigación participativa, eran en un principio la misma entidad y que por diversas discrepancias se escindió esta última, originándose a partir de esta crisis la Asociación de Rumanos de Coslada-San Fernando. El discurso de esta asociación no es muy claro en la medida en que, por un lado, pretenden distanciarse de la I glesia Adventista y ser un espacio para todos los rumanos pero también existen versiones que lo contradicen. La dirigente de esta asociación cuestiona que los adventistas sean tan cerrados pero, por ejemplo, cuando se le pregunta a una mujer ortodoxa sobre las asociaciones de rumanos menciona que no va "porque son adventistas y que para ayudarla preguntan si es adventista y si no lo es no la ayudan o que tiene 
que convertirse". Ésta es simplemente una apreciación que se tiene cuando mencionamos la palabra "asociación".

No obstante, podríamos afirmar, a nivel general, que la Asociación de Rumanos de Coslada-San Fernando no cuenta con un alto nivel de participación rumana ni de representación y aceptación. Aunque oferta una actividad en colaboración con la Asociación Cultural Obatalá, que es la enseñanza del español. Ambas entidades comparten las instalaciones municipales del Centro Sociocultural "La Bufanda". En el presente año el equipo de "Entretod@s" ha comenzado a trabajar con el equipo de con un proyecto que incluye la realización de videoforos ${ }^{4}$ y un boletín de temática rumana, llamado "Dialog".

La Asociación de Rumanos de España Transilvania en la actualidad tiene escasa visibilidad en la vida cotidiana de los rumanos de Coslada, pues no tiene un representante visible en este municipio. Ésta es una asociación con representación a nivel nacional y local que esta interesada en seguir trabajando en Coslada. Ésta además es reconocida por el Ayuntamiento ya que cuenta con un espacio y tienen un horario de atención en el Centro de Asociaciones de Recursos de Coslada en el Centro Cívico de "El Cerro".

También es pertinente señalar la existencia de la FEDROM, pues a través de ésta se pueden crear estrategias de diálogo y mediación que actúen como puente entre el tejido asociativo rumano de Coslada, por un lado, y, por el otro, con el Ayuntamiento. Hemos percibido que su dirigente es una persona que tiene la posibilidad de dinamizar a las asociaciones rumanas desde una perspectiva integradora.

Por último, encontramos a ARES, una asociación que recientemente se ha inscrito en el registro municipal, tiene su ámbito de actuación en Coslada y también en Rumanía (apoyo a españoles en este país y firme denuncia de irregularidades). En el ámbito local dan clases de español para rumanos y los asesoran en derechos y deberes laborales entre otras actividades socioculturales. Cuenta con su sede social en un local privado. Esta asociación discrepa de las políticas y acciones que lleva a cabo la Concejalía de Participación con la población rumana. Además no está de acuerdo con la política de la referida Concejalía, pues plantea que puede ser perjudicial para los intereses generales de Coslada, en el sentido que “(...) es un caldo de cultivo para que den la razón a esos cabezas perdidas, pero que tienen buen corazón, los de la democracia nacional, pues claro si ven la partida de gastos

\footnotetext{
${ }^{4}$ Esta actividad se ha suprimido pues ya existe otra similar y se ha considerado aunar esfuerzos para no doblar los mismos servicios.
} 
y ven lo que se gasta en toda esta gente ilegal (...)". Por el contrario, considera muy positiva la actividad y la organización que posee la Iglesia Adventista.

\section{Red Base Social No Organizada}

La base social configura un conglomerado de redes convivenciales, las cuales no son tan evidentes y no se articulan alrededor de un organismo institucional como los adventistas. En muchos casos, estas subredes se componen por rumanos que conceden mucha importancia al trabajo y es un factor muy importante para entender sus formas de participar. Esto lo podemos observar claramente en esta frase que dice un joven rumano ortodoxo: "rumano viene aquí para trabajar, como yo para ganar dinero".

En general estas subredes de rumanos no organizadas participan poco en actividades colectivas o de asociaciones. Muchos mencionaron la dificultad para participar en el tiempo libre pues aprovechan para realizar las labores del hogar, estar con la familia o simplemente descansar de las largas jornadas laborales, por ejemplo, muchos jóvenes no escolarizados se reúnen para jugar a fútbol los domingos por la tarde en las diferentes instalaciones deportivas municipales.

La mayoría de la gente que logramos contactar es de adscripción ortodoxa pero esto no es lo que los vincula, sus relaciones son más que todo familiares, convivenciales y laborales. Así pues, en los discursos obtenidos existen deseos de tener una buena convivencia con los cosladeños de acogida (para aprender el idioma, conocer sus costumbres y participar de y en ellas), también otros más negativos hacia los mismos rumanos en los que se denuncia las conductas egoístas y delictivas.

En lo referido a la configuración de las subredes de la base social identificadas hemos de señalar que no se establecen tanto por posiciones jerárquicas sino por relaciones horizontales convivenciales.

a) Sub-red Informal de Mujeres

Ésta es una subred que se teje alrededor del ámbito privado, teniendo en cuenta que no es muy común que las mujeres rumanas estén en el ámbito público. Sin embargo, dentro de esta red se pueden observar claras diferencias entre las mujeres. Por un lado, estarían las que poseen un nivel educativo alto y que tienen una mayor consideración de la utilización del tiempo libre. Por el otro, estarían las mujeres que no poseen formación superior, quienes están más interesadas en los aspectos económicos y laborales. De lo cual podría deducirse que sus relaciones se limitan únicamente al ámbito familiar y socialmente cercano. 
Los espacios de encuentro y socialización públicos son muy escasos, sin embargo, hemos evidenciado una subred informal que se vincula a partir de un locutorio donde trabaja una mujer ortodoxa. A este Locutorio asisten constantemente mujeres a conversar, puesto que no van exclusivamente a llamar sino a saludar y charlar. Con ello, constatamos la importancia que tienen los espacios de encuentro y socialización donde se comparten experiencias de la vida cotidiana.

b) Sub-red Informal de Jóvenes Escolarizados

En los jóvenes asentados se encuentran los escolarizados en los Institutos de Educación Secundaria de la ciudad, proclives a conocer la cultura española, aunque se percibe en muchos de ellos un rechazo frontal a la identificación social con sus compatriotas. Aunque existirían diferencias entre los jóvenes pertenecientes a familias con un nivel formativo superior y los que no, pues los primeros gozaban de mayores cuotas de bienestar en su país y, por consiguiente, suelen otorgar mayor importancia a la preservación de sus costumbres originarias. Esto se puede observar en la medida que las madres mostraban mayor o menor preocupación por la forma que sus hijos están creciendo y los nuevos valores que van adquiriendo.

c) Sub-red Informal de Jóvenes Asentados (19-25 años)

Esta subred estaría compuesta por los jóvenes asentados de la base social que se encuentran entre el tramo de edad de 19 a 25 años. Por un lado, ha sido bastante complejo contactar con las mujeres puesto que están dedicadas al ámbito privado $y$, además, no son tan accesibles en el espacio público. Sin embargo, un factor importante en lo relativo a la visibilidad y participación en la comunidad es el nivel formativo pues, en general, las jóvenes que hemos podido contactar en el ámbito público tienen un elevado nivel formativo y, por el contrario, las que permanecen en lo privado no poseen el mismo nivel y habitualmente suelen tener hijos y suelen estar más limitadas a las relaciones familiares y con sus jefes del trabajo doméstico, lo que significa que se les dificulta relacionarse con gente de su misma edad.

Por otro lado, se hace mucho más patente la actividad pública de los jóvenes varones, así como sus discursos. En este sentido, estos jóvenes están construyendo las relaciones sociales a partir del trabajo y la convivencia en el espacio público, como el uso de las pistas municipales de fútbol. La diferenciación por género que hemos descrito se hace más evidente en esta red de la base social "no adventista" en la medida que no se hacen reuniones de jóvenes (como ocurre en el caso de los adventistas), donde si es posible albergar en un mismo espacio y momento a los y las jóvenes. 
d) Sub-red Informal Hombres Asentados

Los hombres de la base social asentados tampoco han sido visibles en el trabajo de campo, sin embargo, de lo poco que hemos podido identificar, están más interesados en mejorar su nivel socioeconómico a partir del trabajo. Estas subredes de tipo económico pueden tener su razón de ser en torno a determinadas actividades, como las empresas de construcción o de transporte propiedad o gestionadas por rumanos.

e) Sub-red Recién Llegados

También encontramos el grupo de los recién llegados de la base social no organizada, que se constituye en un principio a partir de las relaciones familiares y sociales para dar respuesta a las necesidades primarias que se le presentan a su llegada (alimentos, vivienda, búsqueda de trabajo, etc.). Esta subred es bastante visible pues se localiza en la llamada "Plaza de los Rumanos" donde los hombres esperan a que algún empresario español o rumano les dé trabajo en la economía sumergida.

f) Subred Informal Músicos

Otra subred convivencial que hemos localizado es la de músicos y músicas profesionales que hasta ahora muestran mucho interés por el espacio, por lo cual se debería profundizar más en aquélla. Esta subred se configura sobre la base de su afición y profesión. Algunos vínculos vienen de Rumanía, otros se han establecido en los lugares de estudio, como el conservatorio, y otros en su cotidianidad. El objetivo principal de su grupo es la práctica de la música clásica, algunos formando orquestas, otros dando clases de música a particulares.

Desde este estudio de redes se pretende profundizar en el entramado de las relaciones sociales de los rumanos que viven en Coslada, así cómo se empiezan a vislumbrar los distintos vínculos que puedan tener con un futuro Espacio de Encuentro. Podemos concluir afirmando que a pesar de las diferencias manifestadas es posible encontrar los puntos de encuentro y estrategias de negociación para la construcción de un proyecto común.

\section{Los conjuntos de acción}

Nuestro interés se centra en conocer la realidad organizativa de las diferentes manifestaciones de acción ${ }^{5}$ existentes en el seno de la comunidad rumana que habita en Coslada, si éstas pueden contribuir a la creación de espacios

\footnotetext{
${ }^{5}$ Entendemos las Manifestaciones de Acción como las propuestas de los actores sociales que parten de que se convierten en hechos reales, propuesta que se convierte en acción y presenta un resultado visible.
} 
participativos que promuevan la convivencia dentro del propio colectivo y con la sociedad receptora.

Para identificar las acciones que podrían llevar a cabo los posibles conjuntos de acción $^{6}$ para construir el Espacio de Encuentro en Coslada es pertinente, metodológicamente hablando, confrontar los diferentes diálogos percibidos en las diferentes manifestaciones. Esto consiste en identificar las actitudes de las personas y grupos que participan en el transcurso del actuar social que generan acciones relacionales entre diferentes grupos, actores o redes sociales.

Entendemos los "conjuntos de acción" como las diversas relaciones cercanas a nuestro objeto de estudio que agrupan por actividades a diferentes actores, grupos y comunicadores sociales dentro de las diferentes redes y subredes identificadas. No debemos confundir a los "conjuntos de acción" con sus respectivas redes y subredes sociales, aunque los conjuntos se conforman por algunas de las subredes existentes. Lo que los diferencia, es que los conjuntos se conforman por las relaciones entre las subredes que no sólo son propositivas de la acción social, sino que pueden transformar esa propuesta en un hecho visible, en una acción que de algún modo puede que cambie la realidad.

Los conjuntos de acción identificados y analizados son los siguientes: En primer lugar, el conjunto de acción adventista que está compuesto por las algunas subredes que componen la red social articulada alrededor de la Iglesia Adventista. En segundo lugar, el conjunto de acción del Locutorio. En uno tercero, ubicamos una diversidad de grupos y comunicadores conformado por las diferentes asociaciones de Coslada cuyo destinatario es el colectivo rumano, $Y$ en cuarto y último lugar, un grupo de comunicadores convivenciales pertenecientes a la red de la base social no organizada. Estos últimos actores no se pueden catalogar como "conjunto de acción" ya que no se identifican con alguno de los conjuntos anteriormente mencionados y tampoco conforman grupos que propongan alguna actividad o acción. Sin embargo, es importante mencionarlos porque hay algunos rumanos dispuestos a pasar a la acción social mediante sus propuestas y sentido de colaboración para llevar acabo la consecución del Espacio de Encuentro siempre y cuando se cree un espacio que logre reunirlos.

\section{A. Conjunto de acción adventista}

En este conjunto de acción se ubican tres subredes pertenecientes a la red articulada en torno a la Iglesia Adventista. Éstas son los Varones, Mujeres y

\footnotetext{
${ }^{6}$ Los conjuntos de acción, hacen referencia a los distintos tipos de relaciones que se encuentran en los grupos, comunicadores y sectores bases, que son elementos de las redes sociales identificadas ( $R$. Villasante, 1994:40)
} 
Jóvenes, y se diferencian porque se articulan en torno a sus actividades y sus motivaciones que son diferentes. No obstante, aquéllas configuran desde el mismo discurso, el cual es articulado por los Pastores, en especial por el Pastor del grupo de jóvenes, quien estaba muy interesado en fomentar la participación de este conjunto. Por el papel central que jugaba este pastor, podemos decir que tiene algunos rasgos de relaciones personalistas o populistas ${ }^{7}$, ya que a nivel interno mantienen una organización estable con marcadas relaciones de poder a su interior.

En este sentido, el Pastor del grupo de jóvenes tiene un posición central, donde media las relaciones entre los feligreses y las altas instancias de poder eclesial, entre las redes que se articulan al rededor de la Iglesia y hacia el exterior de la comunidad. Esta forma de relacionarse y actuar en torno a un dirigente las llamamos relaciones de "dependencia" debido a que la iglesia se hace imprescindible, ya que gracias a su organización se consiguen ayudas y beneficios de diverso tipo para los miembros de la comunidad.

Observamos que la importancia de la religión dentro de este conjunto de acción, es evidente, ya que desde ella se desenvuelven en la sociedad y de ésta dependen sus acciones. Aunque los adventistas no reconocen que las relaciones al interior de su iglesia se manejan de forma jerárquica, las decisiones y diálogos de los pastores tienen gran influencia. Esto nos sugiere la existencia de niveles de poder que influencian el comportamiento de los rumanos adventistas.

Cabe destacar que las diferentes expresiones y discursos de este conjunto de acción en cuanto a la organización de un Espacio de Encuentro pueden estar influenciadas por su proyecto migratorio, el cual hemos identificado que gran parte de los adventistas tienen la intención de establecerse definitivamente en Coslada, hecho que les predispone a buscar espacios de encuentro diferentes al trabajo. Asimismo, la organización de la iglesia fomenta la participación a través de un modelo con una organización establecida, por lo que esta red se forma con personas que dirigen y coordinan, mientras que otros, participan a un nivel menos profundo. Lo cual pudimos observar en varias de las reuniones que asistimos, por ejemplo, en el grupo de mujeres las monitoras de la reunión dominaban las conversación constantemente y eran las encargadas de organizar las reuniones,

\footnotetext{
${ }^{7}$ Se refiere a aquel grupo o dirigente que mantienen una doble relación hacia el poder por un lado, con contactos privilegiados, y por otro, hacia los sectores de base, a los que les cuenta que gracias a él se pueden conseguir cosas, y así se hace imprescindible. En suma, en este grupo se presentan relaciones de gestión por arriba y de movilización por abajo, con una marginalización de los contactos horizontales hacia otros grupos (R. Villasante, 1994: 41).
} 
convocar y demás responsabilidades. Otro ejemplo, se vio en las reuniones de los jóvenes exploradores donde el Pastor tomaba la palabra y el monitor en menor medida, mientras que el resto del grupo no hablaba.

Su interés por establecerse en Coslada y, en mayor medida, la forma en que está organizada la iglesia determina el interés y las acciones de este conjunto hacia el Espacio de Encuentro y hacia este proceso. Esto lo hemos podido observar en las formas de participar en las entrevistas, puesto que estas han sido coordinadas por medio del Pastor de jóvenes. Para la devolución constructiva tratamos de hacer una convocatoria directa, entregando invitaciones y pegando carteles lo cual no tuvo ningún éxito. Igualmente, lo podemos corroborar en el discurso de una experta temática, donde comenta que "La I glesia Adventista es la red que más estructurada está (...) Los adventistas ya tienen un programa de actividades muy cerrados con fines de semana muy programados y entonces es complicado que participen (en otra cosa diferente) (...) es desde la iglesia donde si que se puede movilizar bastante (...)". Por lo tanto, la movilización y participación de este conjunto de acción para construir un Espacio de Encuentro para todos los rumanos está directamente influenciada por la motivación de sus representantes a participar en dicho proceso.

Por otra parte, en una de las entrevistas a uno de los pastores adventistas, se ratifica la dificultad de convocar y el interés de participar de otros grupos como el de jóvenes exploradores. Afirma: "Tenemos unas organizaciones, asociaciones que intentan hacer cosas no siempre hay mucha, es decir mucha implicación por parte de los rumanos; (...) Yo lo que entiendo es que no se implican tanto, no se interesan, bueno por ejemplo hay grupos que si están dispuestos a colaborar, dentro de la iglesia adventista encontramos el grupo de exploradores de jóvenes, que desde la iglesia se le apoya en sus actividades de salidas de campo y cuestiones de ese tipo. (...) pero en general no se puede esperar una misma respuesta de todos (...)".

Las personas y grupos pertenecientes a este conjunto, se ven altamente influenciadas por el pastor, por lo cual, un repentino cambio de pastor, significaría una nueva posición y visión de participación de los rumanos adventistas hacia el resto de la sociedad del municipio de Coslada. Durante el proceso se ha trabajado con dos pastores, quienes estuvieron muy interesados en apoyar este proceso, por lo cual este conjunto de acción estuvo involucrado en el proceso y participó en varias reuniones y entrevistas para conversar sobre el Espacio de Encuentro. No obstante, este comportamiento puede variar dependiendo del interés de los Pastores tal y como venimos señalando. 
Específicamente el Pastor que coordinaba la parte de jóvenes durante la primeras etapas de este proceso, apoyó permanente las actividades que se planteaban, sin embargo, comentó al equipo que esta situación podría cambiar pues probablemente se realizaría una rotación de Pastores en la Iglesia Adventista de esta zona. Dicho cambio se realizó en la recta final del proceso investigador, justo antes de los talleres de devolución constructiva.

Este hecho generó un cambio en la actitud participativa de este conjunto en el proceso de construcción de un Espacio de Encuentro que venían demostrando en las diferentes actividades realizadas en el trabajo de campo y en el proceso del año anterior. El Pastor entrante que coordina el grupo de jóvenes no tiene el mismo interés, pues lo comentó cuando se le invitó a su comunidad al II Encuentro. Esto se confirmó con la poca presencia activa de los adventistas y miembros del conjunto de acción en el evento, en comparación al año anterior, puesto que para el primero el grupo de mujeres, parte del conjunto de acción, realizó la comida rumana, y el grupo de exploradores, también parte del conjunto de acción, realizó varias actividades socioculturales con los niños.

Además, otros adventistas como el grupo de música, "la Fanfarria", los cuales también estaban invitados a la fiesta, ya que el año pasado habían tocado, tampoco participaron en este segundo encuentro. Lo mismo ha sucedido tanto en las mujeres como los hombres, que habían participado en los talleres de propuestas del año pasado.

\section{B. Conjunto de Acción Locutorio}

Este grupo de acción se crea originariamente a partir de la cesión gratuita de un espacio anexo al locutorio donde se unieron tres grupos para trabajar, los cuales son el de poetas, psicología y trabajo social y el de deportistas. Todos estos comparten la necesidad de crear un espacio representativo donde los rumanos puedan mejorar sus necesidades culturales, deportivas, artísticas, sociales, etc. Por lo cual, nace como una "Alianza local", donde también existen otros conjuntos de acción que son más inestables como sería el tipo de "alianzas locales donde se establece una coordinación entre grupos pero con apenas conexión hacia arriba o hacia abajo, lo que llevará pronto a uno de gestión o uno ciudadanista" ${ }^{8}$. Precisamente, en el proceso de la investigación hemos podido observar las transformaciones en sus formas de actuar y relacionarse.

\footnotetext{
8 I bidem, p. 46.
} 
En tal sentido, planteamos que durante el proceso en este conjunto de acción se han presentando dos tendencias o formas de actuación. En la primera de ellas, es de tipo tecnicista ${ }^{9}$ en nuestro caso la llamamos relación Vertical, en el sentido que se evidencia una gestión desde arriba y presenta varios recelos con otras organizaciones y asociaciones. Su discurso expresa diferencias respecto al trabajo que han realizado estas hacia la población rumana. Esto lo podemos observar en el discurso de uno de los representantes de este conjunto, donde comenta que "las asociaciones quieren siempre acaparar y ser protagonistas en cuanto a la ayuda a la población rumana, además no tienen en cuenta las propuestas que vienen de fuera de su asociación (...) hay personas que quieren hacer cosas buenas para mostrar la cultura y cambiar la imagen de los rumanos (...)".

Esta forma de comportamiento se presenta en el grupo satélite de poetas en el que existe una clara actitud de prejuicio, conflicto y ruptura hacia las otras asociaciones. Este grupo considera que éstas no tienen incidencia alguna en los rumanos y que sus representantes poseen un afán de protagonismo y representación oficial de los rumanos del municipio, y no generan soluciones para la comunidad. Igualmente, la forma de gestión que este grupo plantea, a partir de sus representantes, es que la relación con los sectores de base se debe hacer desde los dirigentes responsables y preparados que van a estructurar y fortalecer su organización.

Por otra parte, se evidencia una tendencia de tipo ciudadanista ${ }^{10}$ en nuestro caso, la llamamos relación cooperativa o solidaria manifestada en el grupo satélite de “Psicología y Trabajo Social" ya que tienen una amplia disposición de relacionarse con los diferentes grupos existentes en la comunidad rumana. Asimismo, este grupo considera fundamental movilizar a la base social en torno a las problemáticas sociales derivadas de la inmigración: desinformación, desempleo y problemas de vivienda. En este sentido, uno de sus representantes comenta: "nosotros, tenemos los conocimientos y la preparación para trabajar en lo que se refiere al tema de asistencia social, estamos dispuestos a colaborar y participar, (...) vemos importante relacionarnos y escuchar los diferentes problemas para empezar a trabajar en este tema...". Sin embargo, el cierto carácter asistencialista que

\footnotetext{
${ }^{9}$ Relación que suele tener una fuerte densidad entre el poder y el grupo que cubre una determinada actividad sectorial en una localidad, y se formula en términos de desconexión, o de conexión débil con otros grupos y con sectores de base. Ibidem, p. 42.

${ }^{10}$ Aquí la mayor densidad de relaciones se produce entre algunos sectores de base y algunos grupos, que se coordinan con algún motivo concreto. Se trata de relaciones de movilización desde abajo donde unos grupos han coincidido con las aspiraciones populares y se plantean a las imágenes del poder que existen tales necesidades. Las relaciones con el poder, suelen ser de negociación o de respeto mutuo, pero no de confianza, por ello, este conjunto de acción presenta procesos donde los discursos de los grupos se van impregnando de los estereotipos recogidos de la base y los comunicadores traducen hacia las bases, decodifican parte de las ideologías y discursos de los dirigentes locales. I bidem, p. 43-44.
} 
plantean, puede llevarnos a pensar que también puede ser un conjunto de acción tecnicista que plantee una relación paternalista hacia la base social en vez de movilización con la base social. Por lo cual, se debería fomentar un trabajo más participativo y formativo con la comunidad y menos exclusivamente de ayuda.

El conjunto de acción del Locutorio, abarca dos formas de relaciones entre sus subredes que se evidencia en los discursos anteriormente mencionados. Dentro de las expresiones y discursos más significativos en cuanto a la organización en referencia a este conjunto de acción, observamos que a este conjunto pertenecen los rumanos que buscan otros espacios de participación distintos al de las asociaciones e iglesias y son personas asentadas con la intención de instalarse permanentemente en Coslada. Uno de los representantes de este conjunto menciona que "la Iglesia Adventista y las asociaciones, tienen ya unas actividades que se han venido trabajando (...) nosotros queremos trabajar otras, como la literatura y la cultura (...) con nosotros también están personas de la iglesia ortodoxa, personas que trabajan y no tienen mucho tiempo para otras actividades (...) las personas que están con nosotros es por que les interesa el tema literario y cultural (...) nos reunimos una vez por semana para hablar de temas literarios y poesía (...)".

Los rumanos pertenecientes a esta conjunto son personas que, por lo general, tienen algún nivel de formación académico o cultural y también están interesados en establecerse permanentemente en Coslada. Este conjunto, está dispuesto a buscar y demandar un espacio donde desarrollar sus actividades y satisfacer así sus necesidades más sentidas. Hasta el momento está compuesto por personas que tienen aptitudes organizativas y participativas y al encontrar un espacio donde desarrollarlas se han organizado y han demostrado su interés por participar en un proyecto, y ya están realizando sus actividades. Perciben la creación de un Espacio de Encuentro como una oportunidad para desarrollar sus inquietudes propositivas y activistas, las cuales se verían fortalecidas ante la presencia de un incentivo real material, como la concreción del espacio físico, en la medida que si llegara a ser real tomarían más fuerza sus pretensiones participativas y organizativas. Referido a esto, podemos ver en la siguiente frase expresada por un poeta adventista: "yo creo que cuando existe una actividad muy clara, muy fuerte, muy buena la gente participa". "Si hay laguna son muchas ranas" (si hay laguna, habrá ranas), (...) cuando existe un centro, cuando existe un taller, cuando existe preocupación; cuando no existe, no hay preocupación". 
Este grupo, al ver resultados concretos romperían el bloqueo que genera la falta de tiempo y a la vez podrían incentivar a sus redes y a otras a participar en lo que ellos estarían organizando. Plantean que "el tiempo se hace cuando existe un espacio, cuando hay muy buena organización de la comunidad rumana, ahí es cuando buscar el tiempo no es un problema (...) Nosotros en cinco minutos cuando somos muchos nos organizamos, de momento no es muy fácil porque no tenemos toda la participación...", señala uno de los poetas. Además, estas motivaciones son palpables a través de las actividades que ellos mismos han organizado, como la reunión del grupo de poetas todos los domingos o un encuentro en Torrejón. Este interés es más visible en el grupo de poetas, sin embargo, son incipientes en el grupo de deportistas y de Psicología y Trabajo Social.

El conjunto de acción del Locutorio no está lo suficientemente cohesionado ideológicamente hablando, grupos que lo componen poseen visiones de organización muy dispares. Por un lado, el grupo de "Centro Academia Metáfora" o de "poetas" se organiza desde una estructura vertical y, por otro, el grupo de “Psicología y Trabajo Social" desde una visión colegiada y horizontal. A pesar de ello, han compartido un mismo espacio físico y una misma idea acerca de la necesidad de ofrecer al diverso colectivo rumano unos servicios culturales y sociales que en la actualidad son poco eficaces.

Por esto mismo, en la última etapa de este proceso se evidenciaron aún más estas diferencias, la comunicación entre estos grupos se ha dificultado hasta tal punto que el grupo o subred de "deportes" dejó de participar en el conjunto de acción. Igualmente, el grupo de "Psicología y Trabajo Social" decidió no seguir trabajando con el grupo de "poetas" y empezó a trabajar conjuntamente con la Asociación Obatalá. Por lo tanto, está en proceso de generar un conjunto de acción distinto ya que esta asociación le ofrece un espacio inmediato para empezar a trabajar.

También, cabe señalar que el grupo de "poesía" continúa realizando sus reuniones todos los domingos en el espacio del locutorio, sin embargo en este grupo se empieza a ver una postura alejada de la idea de la creación de un espacio para todos los rumanos debido a que hay cierto escepticismo de que se vaya a construir. Por lo cual está enfocando sus esfuerzos en constituirse como asociación puesto que consideran que tienen un grupo considerable de personas que ya están empezando a organizarse y tienen la necesidad de tener un espacio físico para seguir realizando sus actividades. Se podría decir que esta sucediendo lo que R. Villasante denomina "Vacío o desencanto" o “Movilización concreta“"11, puesto que

11 “Vacío, apático o de desencanto, donde no hay casi relaciones densas entre los elementos y donde es posible empezar sólo desde lo técnico o desde algo más espontáneo de tipo revuelta“. Ibidem, p. 46. 
se han roto las relaciones entre los grupos organizados de poetas y trabajo social, y las relaciones con el ayuntamiento, que dependen de su participación en el proceso, están decayendo. En este momento sólo queda un gran apoyo de los rumanos interesados en la literatura que siguen asistiendo a las reuniones.

En este sentido, un representante menciona que "las personas que han asistido a este encuentro no son de su agrado, (...) en el Centro Academia Metáfora sólo participan las personas que están interesadas en las actividades culturales y literarias (...)", este conjunto de acción se ha debilitado debido a que se han desligado algunas de las subredes a falta de no llegar a acuerdos en formas de organización y de trabajo.

\section{Grupo de Asociaciones de Coslada}

Dentro de este grupo ubicamos a los representantes, colaboradores y miembros de las asociaciones de rumanos en Coslada. Con esta diversidad de actores el diálogo, intercambio de información e intereses hacia el Espacio se ha presentado débilmente, (como se observa en el sociograma o estudio de redes) A pesar de esto, es importante tener en cuenta el tejido asociativo puesto que tiene su foco de acción social en el colectivo rumano, además en la última etapa se pudo ver el interés de la Asociación Obatalá y del FEDROM hacia la creación del Espacio de Encuentro.

En la débil relación entre el tejido asociativo con la comunidad rumana se evidencia cómo el afán de protagonismos y falta de cooperación entre los diferentes actores sociales generan el alejamiento de la base social. Por ejemplo, al hablar con uno de los representantes de las asociaciones, éste manifiesta su actitud hacia otras asociaciones que trabajan con el colectivo rumano. “(...) en Coslada hay varios bandos, cercanos o aislados al Ayuntamiento y de las personas y de parte de los rumanos... la persona que más ha trabajado he sido yo y las personas que me rodean (...) nosotros no dependemos de nadie y de nada, entonces tranquilamente hemos hecho otra asociación, así no dependemos de nada, y trabajamos para los rumanos de Coslada".

Este tipo de discurso refleja una actitud individualista, donde se está alabando a las acciones propias y desmeritando las de otros colectivos, lo cual genera que las asociaciones carezcan de una base social movilizada, cohesionada y, en definitiva, activa. En tal sentido, uno de los discursos de las personas que acuden a las clases de español dice lo siguiente: "Acudo a las clases de español porque es conveniente

"Revuelta concreta, donde un grupo está conectado con sectores de base, y pronto pasa a un conjunto populista o ciudadanista." Idem. 
para mí, porque sin el idioma es mucho más difícil conseguir trabajo, por eso acudo a las clases, (...) las personas que allí trabajan siempre quieren figurar y mostrar lo que están haciendo, y eso no me gusta (...)". Por otro lado, esta frase demuestra que la base social percibe una actitud populista, la cual también los aleja de estas asociaciones.

Las asociaciones y sus representantes se mantienen en una constante búsqueda de actividades y proyectos, pero todos no generan una movilización o convocatoria representativa, por las actitudes competitivas anteriormente mencionadas, por lo que sus acciones atomizan la comunidad. Esto hace que las personas que participan en sus proyectos no posean una identidad grupal tan interiorizada, como poseen en el caso de los miembros de la I glesia Adventista.

Al observar este grupo de Asociaciones, se puede decir que actúan según sus intereses, también hemos visto que llevan a cabo negociaciones entre ellos para realizar las actividades en las que están interesados.-También se observa que pueden pasar por una actitud individualista de "no necesitar de y a nadie", y mantener una posición populista para mostrar sus acciones $y$, por último, establecer una posición gestionista ${ }^{12}$ donde lleva a cabo la negociación entre ellas con el Ayuntamiento. Por lo tanto, "pueden hacer servicios, pero su discurso y el del sistema están muy próximos y, en cambio, son distantes de los de la base". Nosotros las llamaremos "relaciones de sustento", ya que sus vínculos con los poderes administrativos giran en torno al interés de las diferentes asociaciones en mantener una buena relación con el Ayuntamiento, con el fin de ejecutar y gestionar sus proyectos y conseguir subvenciones. Esto lo pudimos observar, por ejemplo, en un concierto que co-organizó el Ayuntamiento para celebrar la firma del Tratado de Adhesión de Rumanía a la UE, al cual asistieron todos los representantes de las Asociaciones y el cual había sido organizado en coordinación entre ellas (exceptuando a ARES). Contrario al interés que han demostrado en la creación de un Espacio en el cual se ha trabajado mayoritariamente con personas de la base social que se mostraron más receptivas.

La relación interasociativa existente entre la Asociación de Rumanos de Coslada San Fernando y la Asociación Cultural Obatalá se da de una forma abierta y fluida, ya que realizan algunas actividades en conjunto. Esto es importante señalarlo, ya que en relación a la creación y organización de un futuro Espacio de Encuentro sería necesario diseñar estrategias para promover el diálogo entre los diversos

\footnotetext{
12 Son aquellos grupos que mantienen una mayor densidad de relaciones hacía el poder para gestionar servicios, en detrimento de las relaciones que mantienen con la base social; no están totalmente desconectados de los sectores populares, sino que mantienen una relación de escasa participación. I bídem, p 41.
} 
conjuntos y asociaciones; y así promover acuerdos que logren solventar los conflictos y diferencias con la intención de generar negociaciones creativas y constructivas, y trabajar hacia un objetivo común, que abarque el abanico de intereses de los actores implicados.

Frente a la coyuntura actual, podemos ver que un proyecto sólido en el que las asociaciones puedan desarrollar sus intereses y actividades, lograría promover la participación e implicación de estos colectivos. No obstante, en el II Encuentro de Creatividad Social surgió una propuesta que busca generar espacios alternativos para superar las diferencias entre asociaciones y su dificultad para motivar a los rumanos a participar. Para lo cual, uno de los representantes de las asociaciones mencionó la importancia de crear de una Escuela de Participación para el colectivo rumano, "antes de hablar de un Espacio de Encuentro, debemos hablar de una Escuela de Participación y convivencia, para que así se puedan llevar a cabo las actividades propuestas (...) si no existe una conciencia participativa, es muy difícil que la gente se movilice entorno a una actividad (...)". Esta propuesta ya esta en marcha y ha logrado motivar a un grupo de personas de la base social, por lo que podemos ver que es posible fortalecer el tejido asociativo.

\section{Grupo de Comunicadores Convivenciales}

Este grupo hace referencia a los diferentes actores que no sienten ningún tipo de pertenencia o afinidad a los otros conjuntos de la red social y tampoco constituyen un conjunto de acción determinado, pero al ser posibles comunicadores ${ }^{13}$ particulares sus propuestas pueden llegar a generan acciones de movilización social dentro de su colectivo. No los podemos catalogar como conjunto de acción, ya que no conforman redes cohesionadas, ni tienen relaciones con otras redes o actores del colectivo rumano y tampoco están realizando acciones concretas en torno al Espacio de Encuentro. Aún así, estos actores han mostrado mucha disposición y en cualquier momento pueden generar propuestas relacionadas con nuestro objeto de estudio o estar muy interesados en participar. Además, no tienen ninguna relación con las instancias de poder ni con el nivel asociativo.

Hacen parte de este grupo algunas de las subredes de la base social no organizada que promueve algún tipo de acción encaminada hacia la integración y convivencia del colectivo rumano. Un buen ejemplo de estas propuestas, son los partidos de fútbol y las actividades deportivas. Ésta subred informal de jóvenes se autoorganiza los domingos donde se aprovecha un espacio deportivo para conocer, interactuar y,

\footnotetext{
13 Entenderemos por "Comunicadores Convivenciales" como los agentes o actores sociales que sin pertenecer a algún tipo de agrupación u asociación, generan propuestas de acción y estas pueden llegar hacer realidad.
} 
sobre todo, descansar y tener tiempo de ocio junto a otros rumanos. En este sentido algunos de los participantes de estas actividades mencionan: "El único día libre para hacer alguna otra actividad es el día domingo, durante la semana trabajamos y no tenemos mucho tiempo (...). El domingo es el día para reunirse y hablar de otras cosas (...) es el día en el que hacemos deporte aprovechando los espacios deportivos que hay en Coslada (...) hacer deporte es una actividad que casi todos realizábamos en Rumanía".

Entre las diferentes expresiones y discursos observados en el grupo de posibles comunicadores convivenciales, hemos encontrado también un grupo de músicos y músicas rumanos que pertenece a la red de rumanos no organizados que tienen interés en realizar actividades culturales y tienen inquietudes organizativas y participativas, pero no se han organizado ni han encontrado un espacio para poder desarrollarlas. En una charla informal una pianista comentaba que desde su experiencia en la universidad en Rumanía le gustaba participar en grupos para coordinar actividades y organizar eventos culturales, “me gustaría participar en algún grupo de música del municipio, (...) se podría realizar un concierto para darnos a conocer y también para que la gente cambie la imagen negativa que tiene hacia nosotros (...)", En este sentido, al conversar sobre el Espacio de Encuentro, aquélla se vio muy interesada y comenzó a proponer ideas para convocar a más personas a participar de este proceso.

Algunos de estos posibles comunicadores tienen una situación de inestabilidad económica y en algunos casos de irregularidad, por lo cual, tienen dificultades laborales y algunos no saben si van a poder seguir viviendo en España. Así pues, uno de estos comunicadores menciona: "estoy muy preocupado por mi situación aquí en España (...) metí los papeles para poder regularizarme y no se si me den los papeles o no, (...) en el trabajo me exigen tener papeles... (...) si no me salen los papeles probablemente me volveré a Rumanía (...) si no hay papeles no hay trabajo (...) estar en otras actividades es muy difícil, ya que trabajamos mucho, pero si hay algo interesante estaría dispuesto a participar...", Por otra parte, ven a las instituciones como proveedores de servicios, por ejemplo, una experta convivencial comentaba lo siguiente: "para ellos, el Ayuntamiento no es una institución cercana, van a resolver cosas, trámites y la tarjeta sanitaria, se empadronan porque les ofrece facilidades. Las instituciones no les genera confianza por sí mismas".

Las propuestas de acción que generan estos comunicadores tienen relación directa con el objeto de estudio de esta investigación participada, pues buscan el bien colectivo de la comunidad rumana de Coslada, desde una perspectiva integradora. Por ello, si en un futuro se hace realidad el proyecto de crear un Espacio de 
Encuentro lo más probable es que estas personas que proponen y pasan a la acción de forma individual quieran participar y colaborar activamente. Estos actores particulares posiblemente se integrarían en organizaciones que promuevan, desde su punto de vista, el bien común de la diversa comunidad rumana del municipio.

Al observar el comportamiento del colectivo rumano desde los conjuntos de acción, se puede concluir que las diversas formas y situaciones que determinan sus relaciones sociales pueden favorecer tanto la cohesión social como la dispersión de los grupos, en el sentido que los distintos procesos que han vivido los conjuntos de acción nos demuestran que la cohesión es muy débil, porque tienen tendencias a generarse problemas entre los grupos. También hay otras a darle más importancia a la negociación con la institucionalidad o "desde arriba" y a la representatividad del colectivo rumano de la ciudad, y en menor medida a trabajar con la base desde una perspectiva participativa y cooperativa, pues más que todo se plantea un trabajo asistencialista y a veces elitista. Sin embargo, está claro que la concreción del Espacio de Encuentro puede ser un catalizador de los diferentes conjuntos de acción para poder superar las diferencias y fomentar así actitudes o acciones más ciudadanistas o emancipadoras. 


\section{Evolución de los Conjuntos de Acción}

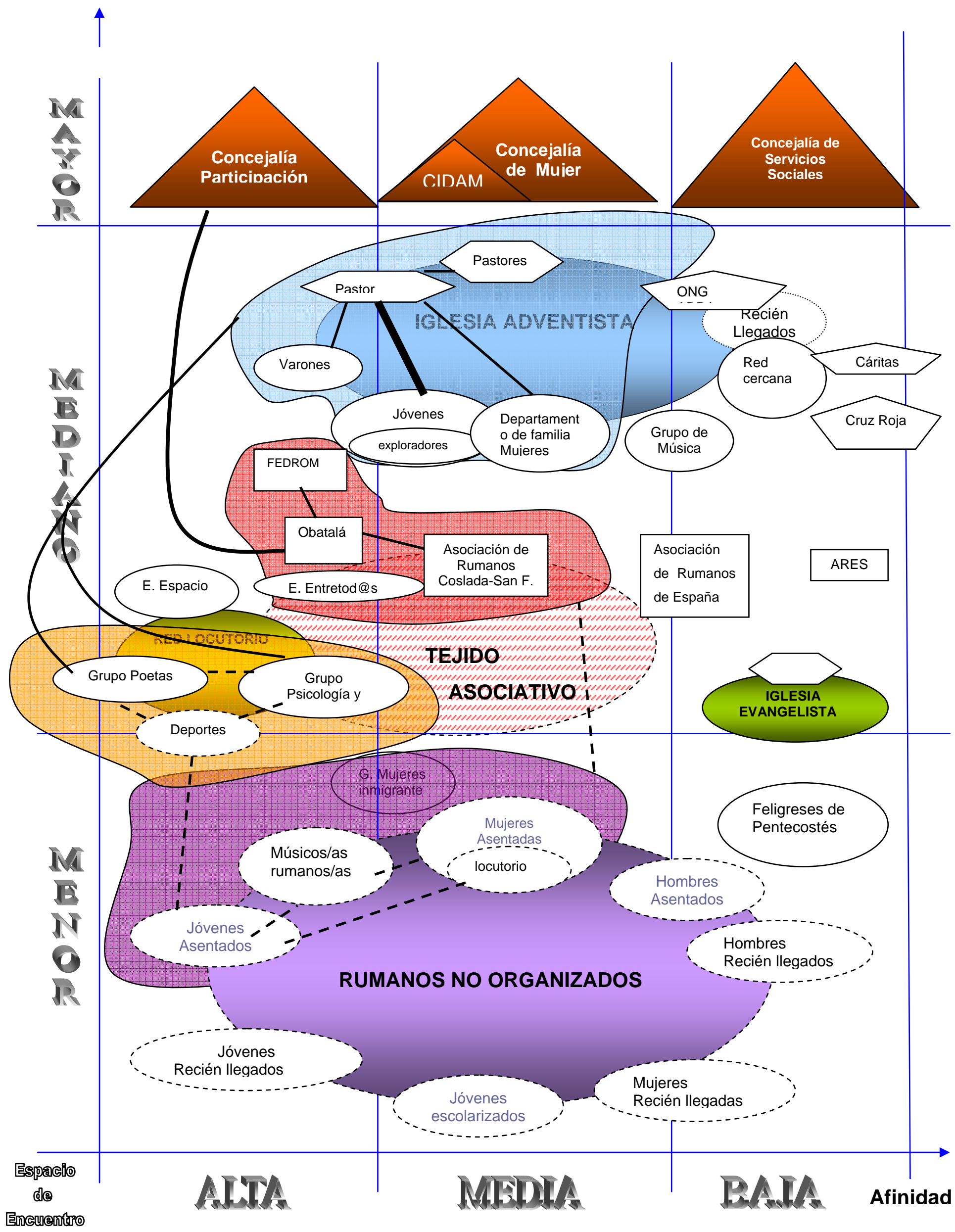




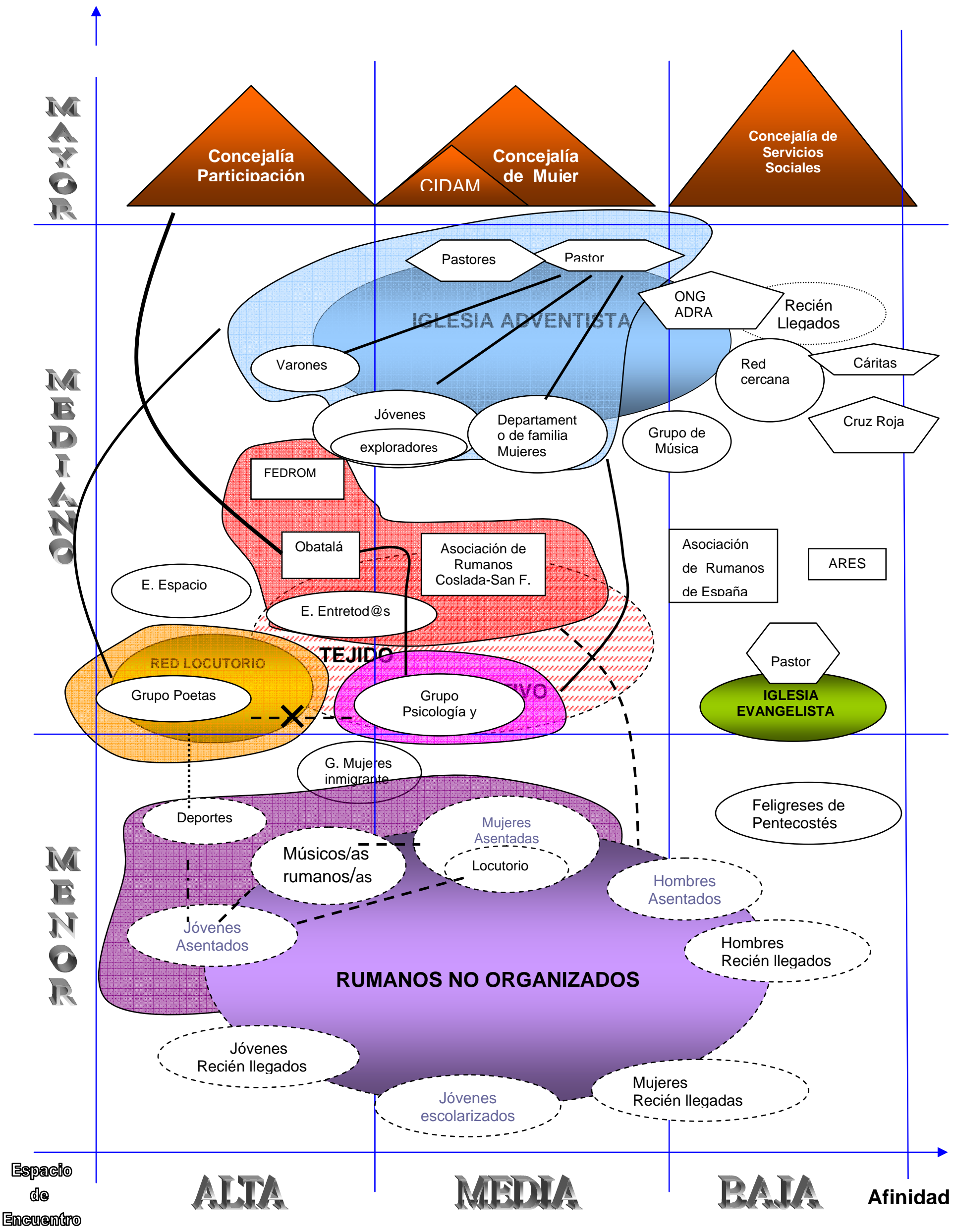




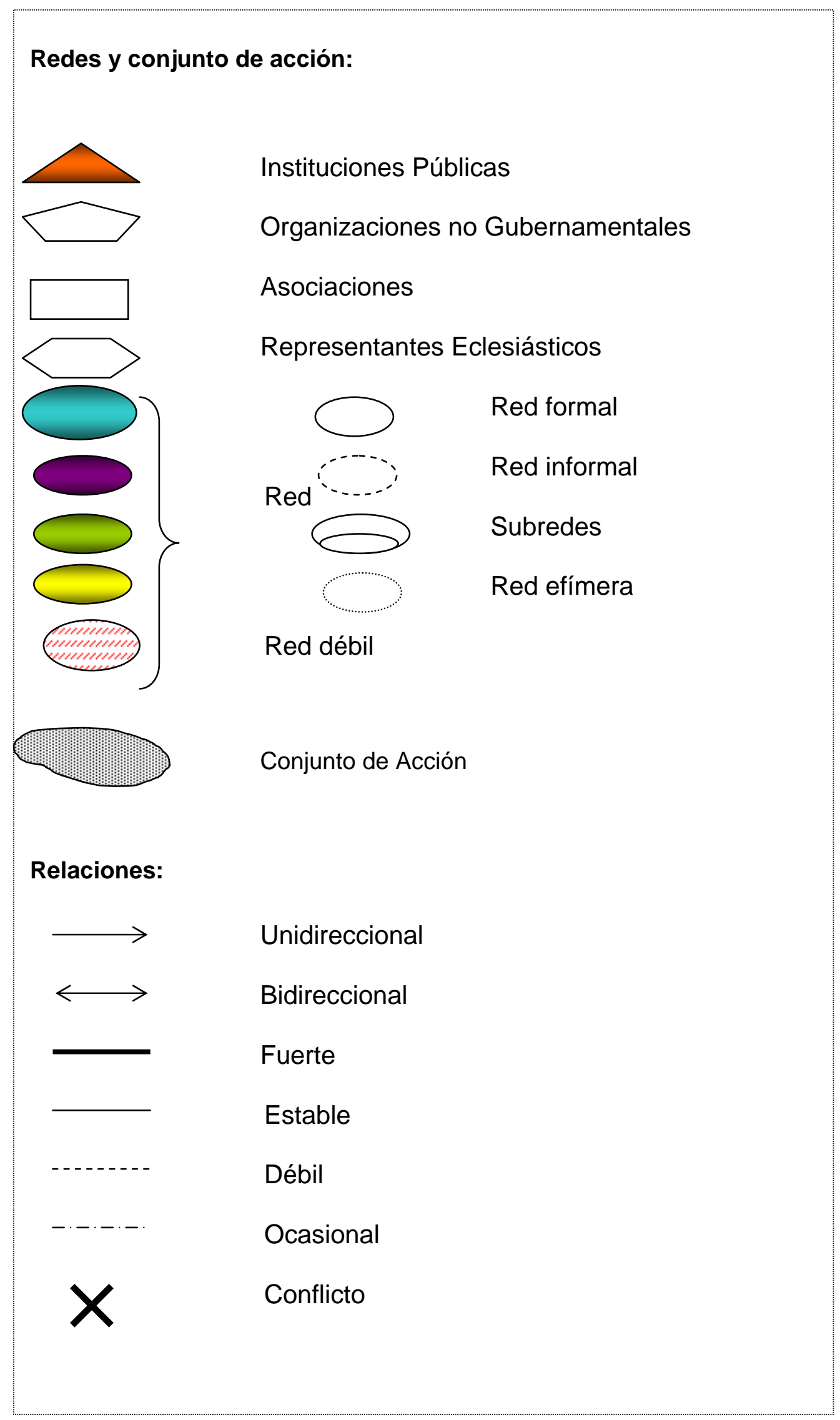

Leyenda. Evolución de Conjuntos de Acción 


\section{Bibliografía}

AA.VV. “CORNISA"- C.S.C. “MARIANO MUÑOZ" (2004). Memoria 2003-2004. Sin publicar.

Cachón, L. (2002): "La formación de la España inmigrante: mercado y ciudadanía". En Revista Española de Investigaciones Sociológicas, no 97, Enero- Marzo, pp. 95126.

CIMAS (Octubre 2000/01): Estudio Sobre La Participación Social y Políticas Públicas En El Distrito De Usera. Patrocinado por el Ministerio de Trabajo y Asuntos Sociales. Cortina, A. (1999). Ciudadanos del mundo. Hacia una teoría de la ciudadanía. Madrid: Alianza Editorial.

Fundación Kaleidos. RED (2003). Equipamientos Municipales de Proximidad. Gijón: Ediciones TREA.

García Canclini, N. (1990). Culturas híbridas: estrategias para entrar y salir de la modernidad. México: Grijalbo.

Martiniello, M. (1998). Salir de los Guetos Culturales. Barcelona: Ediciones Bellaterra.

Rodríguez Villasante, T. (2002). Construyendo Ciudadanía. Sujetos en movimiento: redes y procesos creativos en la complejidad. Vol. 4. Madrid: CIMAS.

Rodríguez Villasante, T. (Coord.) (1994). Las ciudades hablan: identidades y movimientos. Caracas: Editorial Nueva sociedad.

Rodríguez Villasante, T., Montañés, M. y Martí, J . (2002). Construyendo Ciudadanía. La investigación social participativa. Vol. 1. El Viejo Topo, Barcelona. 2aㅡ Ed.

Rodríguez Villasante, T., Montañés, M. y Martí, J. (Coords.) (2003). Prácticas locales de Creatividad Social. Vol. 1. El Viejo Topo, Barcelona. 2a Ed.

Sánchez, J., Bru, P. y Basagoiti, M. (2003). Proyecto "Cornisa". Sin publicar. 